\title{
The Art of Modulating, Preludizing, and Fantasizing: Schenker's Thoughts about Keys and Key Change Reconsidered
}

A Arte de Modular, Preludiar e Fantasiar: 0 pensamento de Schenker sobre tonalidade e modulação reconsiderado

John Koslovsky Conservatorium van Amsterdam john.koslovsky@ahk.nl

Matthew Brown ${ }^{2}$ Eastman School of Music mbrown.esm@gmail.com 


\section{Abstract}

Although Heinrich Schenker certainly changed his mind about many topics, he never waivered in his belief that 1) current ways to explain modulation were fundamentally flawed; and 2) that modulation is best learned by improvising preludes and fantasies. To explain these points, Part I reconsiders Schenker's critique of Max Reger's Beiträge zur Modulationslehre (1903) and Salomon Jadassohn's Die Kunst zu Modulieren und zu Präludieren (1890) and describes three types of modulation endorsed by Schenker in his Harmonielehre (1906): 1) [diatonic] reinterpretation; 2) chromaticism; and 3) enharmonicism. Part II then shows how Schenker not only dispensed with the traditional concepts of relative, close, and distant keys, but he eventually proposed that modulations arise at the foreground for contrapuntal, even motivic reasons. Finally, Part III uses Schenker's claims about modulating and preludizing to analyze Beethoven's "Two Preludes" in C major, Op. 39, both of which modulate "through all twelve major keys."

Keywords: Heinrich Schenker; Ludwig van Beethoven; Modulation; Preludes; Fantasies

\section{Resumo}

Embora Heinrich Schenker certamente tenha mudado de ideia sobre muitos tópicos, ele nunca renunciou à sua crença de que 1) as formas correntes de explicar a modulação eram fundamentalmente falhas; e 2) que a modulação é melhor aprendida improvisando prelúdios e fantasias. Para explicar esses pontos, a Parte I reconsidera a crítica de Schenker do Beiträge zur Modulationslehre de Max Reger (1903) e Die Kunst zu Modulieren und zu Präludieren de Salomon Jadassohn (1906): 1) reinterpretação [diatônica]; 2) cromaticismo; e 3) enarmonismo. A Parte II mostra como Schenker não apenas dispensou os conceitos tradicionais de tonalidades relativas, próximas e distantes, mas finalmente propôs que as modulações emergem no nível frontal (foreground) por razões contrapontísticas, até mesmo motívicas. Finalmente, a Parte III usa as afirmações de Schenker sobre modular e preludiar para analisar os "Dois Prelúdios" de Beethoven em Dó Maior, Op. 39 , os quais modulam "através de todas as doze tonalidades principais."

Palavras-chave: Heinrich Schenker; Ludwig van Beethoven; Modulação; Prelúdios; Fantasias.

\footnotetext{
1 John Koslovsky is on the music theory faculty at the Conservatorium van Amsterdam and holds an affiliate research position in the humanities at Utrecht University. His research deals with the history of Schenkerian theory, music analysis and the history of music theory. He is currently co-editing a book volume (with Michiel Schuijer) on performance theory, entitled Researching Performance, Performing Research, and is currently writing a book on the work of Felix Salzer and its impact on post-WWII music theory. He is a member of the Schenker Documents Online project and former president of the Dutch-Flemish Society for Music Theory.

2 Matthew Brown is Professor of Music Theory at the Eastman School of Music. He is author of four books—Debussy's 'lbéria': Studies in Genesis and Structure (Oxford, 2003), Explaining Tonality: Schenkerian Theory and Beyond (Rochester, 2005), Debussy Redux. The Impact of His Music on Popular Culture (Indiana, 2012), and Heinrich Schenker's Conception of Harmony with Robert Wason (Rochester, 2020)—and nearly fifty articles/reviews in such periodicals as the Journal of Music Theory, Music Theory Spectrum, and Science. Brown is a founding member of TableTopOpera, a group of Eastman faculty and friends, that specializes in digital multi-media projects, and is involved with various projects in AR/VR at the University of Rochester's Medical Center and the Department of Electrical Engineering.
} 
Although Heinrich Schenker certainly changed his mind during the course of his career, he never wavered in his beliefs that traditional ways of explaining modulation were fundamentally flawed and that modulation is best learned by improvising preludes and fantasies. Not surprisingly, perhaps, they were themes that Schenker first addressed in his Harmonielehre of 1906: the book not only contains his most detailed account of modulation, but it also ends with a section on "Die Lehre vom Modulieren und Präludieren" (SCHENKER, 1906, p.445452). ${ }^{3} \mathrm{He}$ touched on these issues a few years later in the first volume of Kontrapunkt (1910), complaining that "today's musicians are no longer able to improvise preludes or modulations, they are no longer able to execute cadenzas and fermatas in their leisure time!" (SCHENKER, 2001 [1910], p.296). Fifteen years later, in his essay "Die Kunst der Improvisation" (1925), Schenker revisited the interconnections between modulating and preludizing: that essay, which focuses on C.P.E. Bach's guidelines for improvising preludes and fantasies, begins with a long excursus on keys and key change (SCHENKER, 1994 [1925], p.2-19). And, in Der freie Satz (1935), Schenker again dismissed existing explanations of key change as "the most fatal error of conventional theory" ("der verhängnisvollste Fehler der üblichen Theorie") and stressed that "the ability to compose extemporaneously, to fantasize, and to preludize-the beginning of all [artistic] creation-lies only in a sense for the background, middleground, and foreground" (SCHENKER, 1935, pp.26 and 22).

Though well documented, Schenker's harsh reactions to traditional accounts of modulation have created confusion about the role the concept plays in his work. In The Essence of the Musical Artwork: An Introduction to the Teachings of Heinrich Schenker (1934), Oswald Jonas echoed Schenker's purported aversion to modulation through a citation of the opening of Beethoven's piano concerto in G major (Op. 58, mm. 6-14): "How consciously the composer grounds a transient coloration in the [diatonic] system, and how incorrect the assumption of traditional theory is in describing such a passage as based on 'modulation' and the exploration of other keys..." (JONAS, 1934, p.57-58). Later, in his "Introduction" to Schenker's Harmony (1954), Jonas was more explicit: "'Tonicalization,' however, affects only the subordinate strata-the middleground, in Schenker's terminology-or the surface phenomena of a composition-its foreground. It never takes place in the background, the ultimate stratum expressing the whole. Accordingly, Schenker later on rejected the concept of modulation in its strict sense, although in Harmony this concept is still retained" (SCHENKER, 1954 [1906], xxii). Carl Schachter, however, has been more circumspect: having noted that Schenkerian theory "greatly reduces" the scope of modulation as compared to rival theories, Schachter conceded that "a greater emphasis on key change" is surely in order (SCHACHTER, 1987, p.289-90). In response, he has tried to reconcile Schenker's ideas with traditional views "by showing the connections among foreground tonicizations, large-scale modulations belonging to the middleground, and inclusive background structure" (Ibid., p.315). According to Schachter, this procedure "may give more attention to the fluctuations

3 Throughout this essay we combine our own translations from Schenker's German text with citations from existing English translations (sometimes with slight alteration, where indicated). In each case, the year cited will indicate from which source we draw (when drawing on an existing English translation, the date of the original publication is also given in square brackets for reference). Only in cases where clarification is needed will the original German text be provided in a footnote. We would like to thank Mike Zachary for his careful proofreading of this article. 
of the foreground than [Schenker] did," but it is "in no way contradictory to the spirit of [his] approach" (Ibid., p.315).

The goal of this paper is to extend Schachter's arguments, by focusing on Schenker's own comments about modulation and on how they illuminate the structure of preludes and fantasies. The paper has three parts. Part 1 begins by reconsidering Schenker's reaction to contemporary accounts of modulation, especially those found in Max Reger's Beiträge zur Modulationslehre (1903) and Salomon Jadassohn's Die Kunst zu Modulieren und zu Präludieren (1890). It then shifts to Schenker's account of modulation in Harmonielehre and the sorts of foreground fluctuations mentioned by Schachter. Part II then addresses the matter of key relations, especially Schenker's critique of the traditional concepts of relative, close, and distant keys, and explains what secondary key areas are actually possible in monotonal compositions. It endorses Schenker's view that modulations ultimately arise at the foreground for contrapuntal, even motivic reasons. Finally, Part III reconsiders the connections between modulating and preludizing by analyzing Beethoven's "Two Preludes" in C major, Op. 39, which modulate "through all twelve major keys" ("durch alle Dur-Tonarten"). Besides showing connections between these pieces and Beethoven's Fantasy Op. 77, we suggest that they belong to a pedagogical tradition that extends back through Christian Gottlob Neefe to C.P.E. Bach and forward through Beethoven to Ferdinand Ries and Carl Czerny.

\section{Schenker and the Modulation Treatises}

It is hard to overestimate the extent to which Schenker's thinking about music theory was shaped by his dissatisfaction with the ways in which it was taught at the turn of the $20^{\text {th }}$ century. Schenker criticized all aspects of contemporary theory pedagogy. He railed against the authors of various Harmonie- and Kontrapunktlehren, as well as popular approaches to Formenlehre. Not surprisingly, perhaps, the topic of modulation was firmly in his sights. Upon reading Reger's Beiträge zur Modulationslehre, Schenker wrote in his diary that it is "[a] trivial work that nothing in the world can excuse: slipshod and limited; foolishly complacent and childish." Around the same time, he also lambasted mm. 1-8 from Reger's Piano Quintet no. 2 (Op. 64, 1901-2) in a footnote to 589 of Harmonielehre. That critique points to the work's lack of tonal plan and especially to the ambiguous way in which it connects the movement's home key of $\mathrm{C}$ minor with the subordinate key of $\mathrm{Eb}$ major. According to Schenker, the home key is never defined properly in the movement: "Where is the solution to this problem? Nowhere. There is no place in the work that gives information about the principal key, and only with great toil do the elements that occur before connect to the elements that come after. And, when such an occasional connection arises it is too meager, too trivial, and too short. There is no plan in the keys (Tonarten), no plan in the apparent keys (Scheintonarten)-everything is just one large, irrational and continuous mass" (SCHENKER, 1906, p. 222, n. 1).

4 Schenker, diary entry, 15 March 1899 (schenkerdocumentsonline.org; transcription and translation by lan Bent). Note that the date of this entry is incorrect: the entry is otherwise undated, and most likely comes from 1907 or 1908, shortly after Reger received an appointment at the University of Leipzig (see fn. 2 in SDO entry). 
Twenty years later, Schenker took issue with Reger's theoretical approach to modulation in an analysis of his Variations and Fugue on a Theme by Johann Sebastian Bach. After claiming that Reger's own variations are "based on a grossly overdriven fussiness in the connection of immediately adjacent chords, which thwarts larger-scale connections, and therefore renders outer-voice counterpoint and composing-out impossible," he noted that Reger's explanations of modulation exhibit the same obsession with local chord successions (SCHENKER 1994 [1926], p.116). Citing two modulatory progressions from Reger's Modulationslehre, one from $C$ major to $F \#$ major (Figure 1a), the other from $C$ major to $C \#$ major (Figure 1b), Schenker insisted that such abstractions are not only based on chords that are not composed-out (unauskomponierte Klänge), but they also lack the unifying element of the "unfolded motive" which gives birth to that composing-out. He concluded that "motives and composing-out progressions do not lead so simply from $C$ major to $F \#$ major or to $C \#$ major, if such a thing could be expected of them at all" (Ibid., p.117).

a) From $\mathrm{C}$ major to $\mathrm{F} \#$ major (Ex. 6)

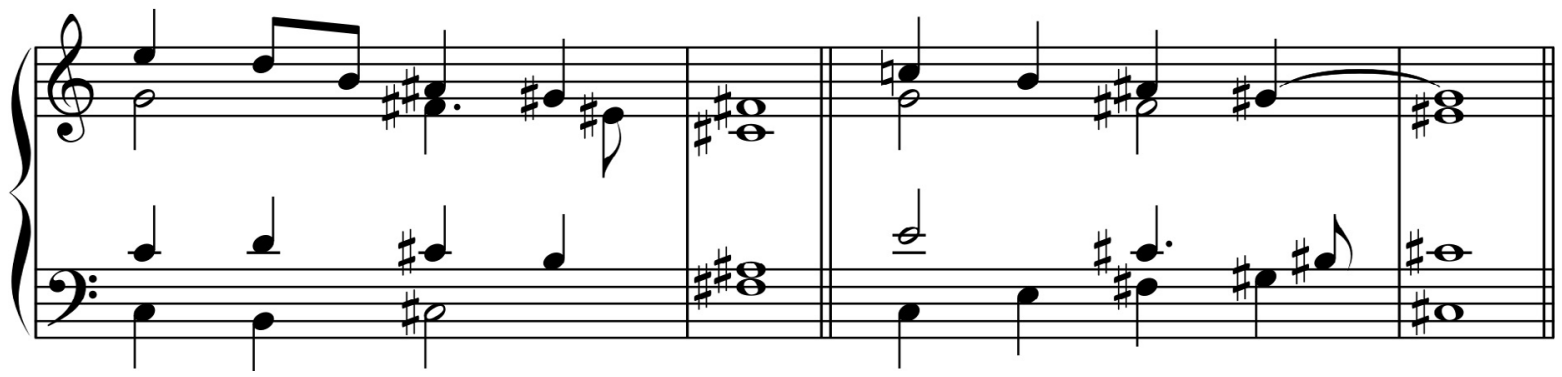

Figure 1: Two modulatory progressions from Reger's Modulationslehre (Exs. 6-7).

Reger was not, however, Schenker's only target for attack: in his Harmonielehre he also took issue with Salomon Jadassohn, who clearly foreshadowed Reger in seeking the shortest path from one key to another and in suggesting that the most fleeting of chords take part in a modulation (SCHENKER, 1906, p.446-447). Hostile to both points, Schenker singled out one particular progression from Jadassohn's treatise Die Kunst zu Modulieren und zu Präludieren (1890) in which the author identifies three separate key areas-A major, G minor, and $C$ major-within the space of just two measures (see Figure 2). The topmost system of the example (omitted by Schenker) is intended to show the derivation of the F\#-diminished seventh chord from a diatonic II7 in C major. Were this latter chord to be used literally, the progression would (in Jadassohn's words) result in a "completely authentic cadential closure" (vollkommene authentische Schlusskadenz) confirming the modulation from A major to $\mathrm{C}$ major. The use of the altered sonority, in Jadassohn's view, adds yet another modulatory layer to the progression, without disturbing the cadential motion to $\mathrm{C}$. Jadassohn commented on this and similar examples: "[i]t remains only to be demonstrated how, through the chromatic alteration of intervals of the second scale step [II], the closing cadence becomes a means of modulation, and how the cadence by itself is already able to execute a brief transition" (JADASSOHN, 1902 [1890], p.159). 

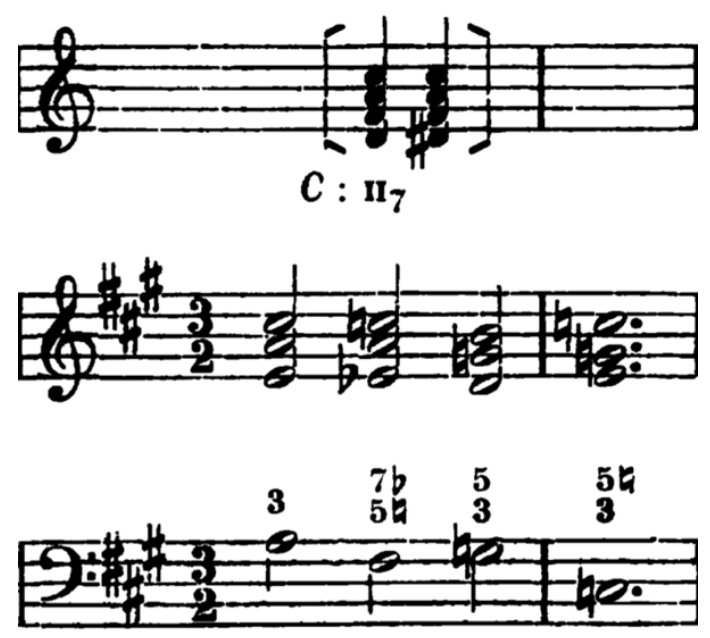

$$
\text { A:Ig: } \operatorname{vin}_{7}^{0} C: \mathrm{V} \quad \mathrm{J}
$$

Figure 2: Jadassohn, Die Kunst zu Modulieren und zu Präludieren, p. 160 (Ex. 158b).

Schenker's dissatisfaction with Jadassohn's example echoes his reaction to Reger's work. While he saw no great problem in the abstract progression of chords per se (though he indicated in a footnote that they could more easily be viewed as chromatized chords in C major, the goal of the passage), Schenker complained about the scope of Jadassohn's interpretation: "Instead [of supplying the progression of essential harmonies with motives of greater or lesser duration and setting the progression in a free rhythm], what do we see in Jadassohn's example? He gives each harmony the same weight of a half note, sets the harmonies simply in triads and seventh chords (the most blatant tautology!), and already believes to have achieved the effect of a modulation, whereas in reality he has stopped at the 'unfree' (if twice written) sketch" (SCHENKER, 1906, p.446-447). ${ }^{5}$

In his defense, Jadassohn did provide a "free" working out of a "modulatory progression" for an entire prelude at the very end of his treatise, based on the scheme in Figure 3. Jadassohn then worked out his scheme with different keyboard figurations, including arpeggiated block chords in closed position, arpeggiations spanning multiple registers, and arpeggiated textures including passing tones. Nevertheless, Schenker would likely remain unpersuaded: first, because the "modulations" represented in Jadassohn's scheme can easily be construed in $\mathrm{C}$ major using tonicization and mixture (he would have been especially perturbed that the G pedal point is erroneously labelled "I"); and second, because Jadassohn's realizations basically present the harmonic progression shown above in literal, chord-by-chord fashion (with the exception of some surface passing tones), and they neglect to compose out each Stufe motivically or contrapuntally. In other words, even Jadassohn's attempt to breathe

\footnotetext{
5 "Statt dessen, was sehen wir bei Jadassohn? Er gibt jeder Stufe gleichmäßig den Wert einer halben Note, setzt die Stufen einfach in Drei- resp. Vierklänge um (die offenkundigste Tautologie!)[...] und glaubt so schon die Wirkung einer Modulation zu erzielen, wo er doch noch immer bei der unfreien, nur eben doppelt geschriebenen Skizze stehen geblieben ist." The added passage substituting for Schenker's "Staat dessen" is based on the paragraph immediately preceding this quote.
} 
life into the progression fails. Instead of relying on such pseudo voice-leading progressions, Schenker simply advised teachers to offer a modulatory plan using words, Roman numerals (Ziffern), or "at most" a progression of roots in a bass clef (SCHENKER, 1906, p.447).

All of this underscores one of Schenker's pet peeves with all harmony instruction: its desire to reduce the hearing of harmony to a series of block chord progressions and to reify such block progressions using musical notation. Not only that, but such reified progressions also oblige a theorist to account for voice leading within the realm of harmony itself, thereby making rigid something that ought to be set free. Since Schenker regarded harmony as a system of "ideally moving forces" (ideell treibenden Kräften), he assigned voice leading to the realm of counterpoint, where it has greater capacity for composing out and ultimately prolongation. Such composing-out is, of course, typical of free composition, something that Schenker underscored in his discussion
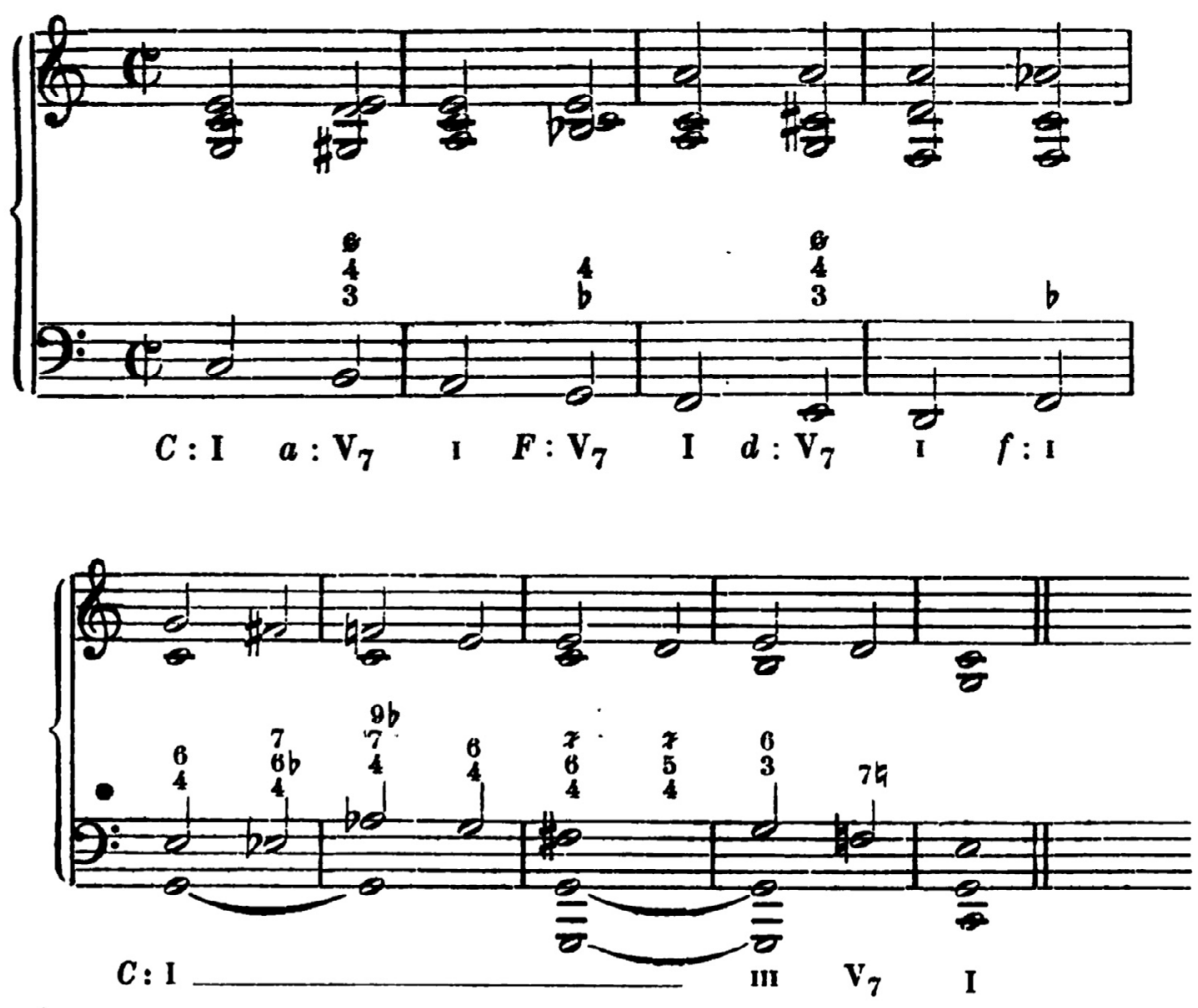

Figure 3: Jadassohn, Die Kunst zu Modulieren und zu Präludieren, pp. 183-184, Ex. 185a.

of modulating and preludizing: "Modulating and preludizing-even in its most primitive case of a study example!-should show all the characteristics of a free composition, viz, a freely invented motif, free and variegated rhythm, as well as the harmonic tools offered by the diatonic system, the principles of mixture, chromatic alteration, and tonicization, and free step progression, with its inherently peculiar psychology" (SCHENKER, 1954 [1906], p.336 [with slight alteration]). 
While most people associate Schenker with his later theory of transformational levels governed by the Ursatz, he still offered important insights in Harmonielehre both about the nature of modulation and about the ways it is often described in theory textbooks. The latter largely stemmed from three sources: 1) Schenker's deep concern for the psychology of harmony more generally (evident already in his published lecture on Der Geist der musikalischen Technik [1895] and in his essay Das Tonsystem [ca. 1904-5]); ${ }^{6}$ 2) his frustration with abstract harmonic progressions that have little connection with actual pieces (such as can be found in the treatises on modulation by Reger and Jadassohn); and 3) his observation that most theorists only considered modulation on a chord-by-chord level, with no concern for the broader composing-out (Auskomponieren) of a harmony. But Schenker did not reject familiar accounts of modulation entirely, at least not in Harmonielehre. One way he accepted the past was by construing modulation in terms of a chord's potential to carry multiple meanings (Mehrdeutigkeit): this not only creates smooth connections between two keys, but it also enables a chord to be "heard" in different keys simultaneously ${ }^{7}$ And, like many of his predecessors, Schenker described three types of modulation: 1) Modulation through the reinterpretation of a diatonic Stufe (what Schenker simply calls "Umdeutung"); 2) Modulation through chromaticism (Modulation durch Chromatik); and 3) Modulation through enharmonicism (Modulation durch Enharmonik).

As it happens, Schenker made a subtle distinction between the first two categories. In the first, he drew on the notion of "silent reinterpretation" and "silent modulation" to signal how an essential harmony (Stufe) in one key can be reconfigured as an essential harmony in another. While this idea resembles the modern notion of the "pivot chord," it actually brings in a discussion of mixture and tonicization as they relate to "reinterpretive modulation." Take, for example, Schenker's analysis of Chopin's second prelude, mm. 7-23. ${ }^{8}$ As shown in Figure 4, he indicated that these measures project four different keys: G major, B minor, D major, and $A$ major/minor, the key that closes the work. Having passed quickly from $G$ major through $B$ minor to D major ( $\mathrm{mm}$. 7-9), Chopin sets up the expectation of a cadence in D major at $\mathrm{m}$. 11, but when the diatonic "I" chord is expected, Chopin adds a chordal seventh and an element of chromaticism (Schenker writes "Chroma") to the root of the chord, resulting in the half- diminished sonority $D \# / F \# / A / C \#$. Despite such inflections, Schenker still regarded this sonority as being based on $D$ (hence "\#I"). For him, the $D \#$ ultimately arises to tonicize the dominant of $A(" \# I V ")$ and strengthen the $V-I$ cadence in

6 The latter essay, never published during Schenker's lifetime, has been recently translated with commentary by Robert Wason as "Foundations of Tonal Systems" (see WASON AND BROWN 2020, p.425-453). William Pastille's translation of Schenker's "Geist" essay can be found in COOK, 2007, p.319-332.

7 The notion of Mehrdeutigkeit (as well as harmonic reduction using Roman numerals in general) is first attributed to Georg Josef Vogler in his 1802 Handbuch zur Harmonielehre, and was further taken up by theorists such as Gottfried Weber and Simon Sechter (who passed it along to Anton Bruckner, Schenker's own harmony instructor at the Vienna conservatory). For general accounts of the notions of Modulation and Ausweichung in eighteenth- and nineteenth-century. German music theory, see MITCHELL, 1970; and BLUMRÖDER, 1983.

8 This analysis was omitted in the 1954 translation. 

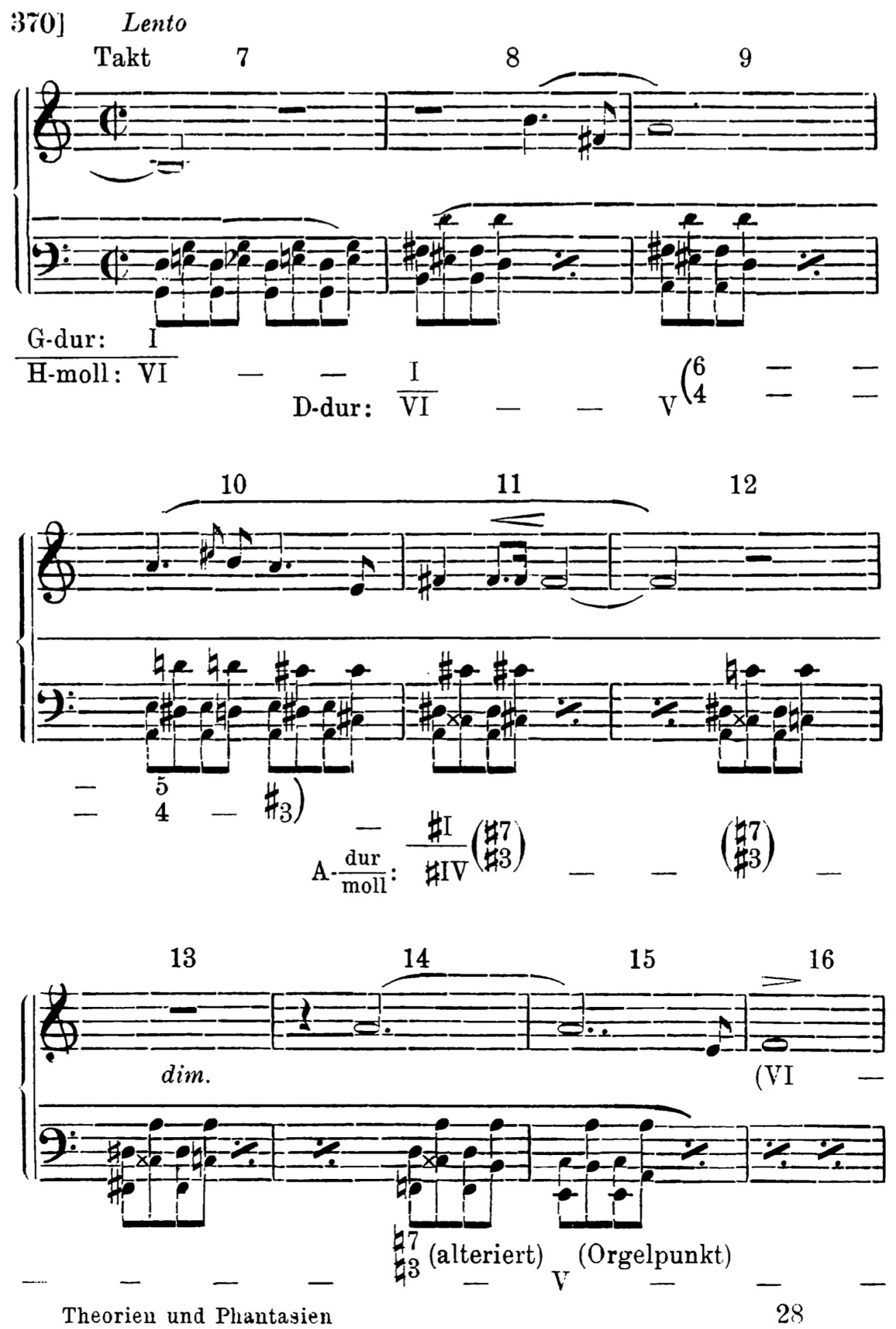

Figure 4: Schenker's analysis of Chopin, Prelude in A minor, mm. 7-16 (Harmonielehre, p. 433, Ex. 370).

A major/minor in mm. 15-23. And between the arrival of \#I $\#$ IV at $m .11$ and $V$ at $m .15$, the $\mathrm{D} \#$ chord is transformed chromatically even more by lowering its seventh and then its third: 
such alterations result in three different sonorities, all supported by a single Stufe: half-diminished (m. 11), then fully-diminished (mm. 12-13), and finally "altered" (alteriert, a "French" augmented $4 / 3$ chord in modern parlance, m. 14). The chromaticism itself does not explain the modulation, since the "fundamental" D has not changed, but rather enriches its effect through tonicization.

Contrast this understanding of modulation (based on "diatonic" reinterpretation) with one based on what Schenker calls "chromatic modulation." In this case, the chromatic element itself becomes the means by which the music modulates. To illustrate what he had in mind, Schenker considered two moments from the Prelude in Eb major in the second book of Das wohltemperierte Klavier. The first, starting at $\mathrm{m}$. 19, involves a chromatic modulation from $\mathrm{Bb}$ major to $\mathrm{C}$ minor (see Figure 5). Though not shown here, $\mathrm{Bb}$ is established as a local tonic by a cadence in $\mathrm{m}$. 12. At the point of modulation at $\mathrm{m}$. 19, it is transformed (just like Figure 4) by raising the root of the original tonic (hence "lㅣ"). But, instead of describing the diatonic $\mathrm{Bb}$ chord as a "silent reinterpretation" within C minor (i.e., bVII, locally transformed into घVII), Schenker treats the version with the raised root as an independent harmony in $\mathrm{C}$ minor (just VII). According to him, this chromatically altered chord is a product of mixture (Mischung), as his Table III and Ex. 75 from Harmonielehre demonstrate (see SCHENKER, 1906, pp.117 and 110 respectively).

The second moment in $\mathrm{mm} .35-43$ of the prelude also features a modulation by ascending step (see Figure 6). This time, however, the modulation is a two-stage process. Coming off of a cadence in $\mathrm{Eb}$ major at $\mathrm{m}$. 35, Schenker immediately reinterprets the $\mathrm{Eb}$ chord as $\mathrm{V}$ in $\mathrm{Ab}$ major (thus "modulation through reinterpretation"), from which the same phenomenon as before takes place. Then, at the end of $\mathrm{m}$. 39, Ab's root is altered to Ah, allowing Schenker to treat the chord as VII in Bb major. This latter key is short-lived, however, as it undergoes the same process of chromatic modulation as $\mathrm{Ab}$ major two measures later, in order to reach $\mathrm{C}$ minor (the same process we saw at m. 19). But the music immediately invokes a third key, $G$ minor (m. 42), which exerts its influence at the very moment $C$ minor arrives. These two keys compete with one another for perceptual significance for the ensuing two measures, when $\mathrm{G}$ minor finally takes hold. A chromatic modulation has, then, immediately been followed by a modulation through reinterpretation.

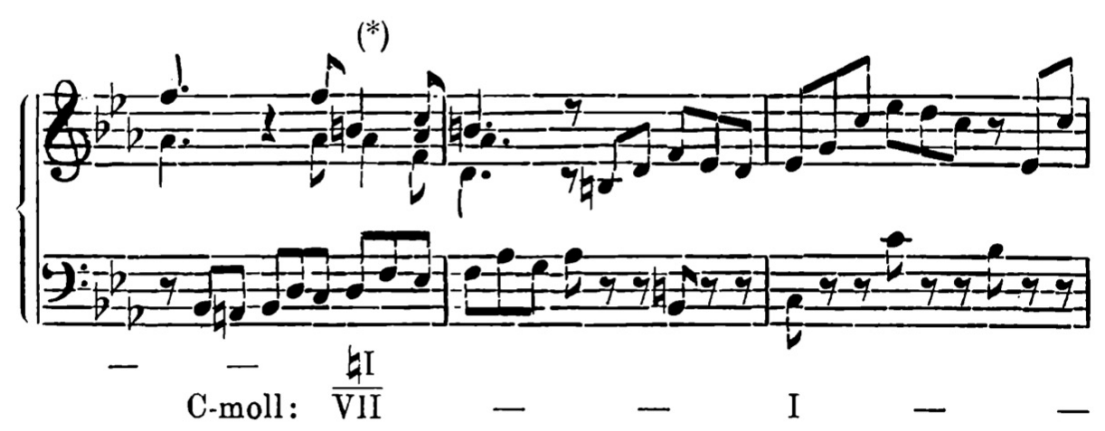

Figure 5: Schenker's analysis of Bach, Prelude in E major (WTC II), mm. 19-21(Harmonielehre, p. 438, Ex. 371). 

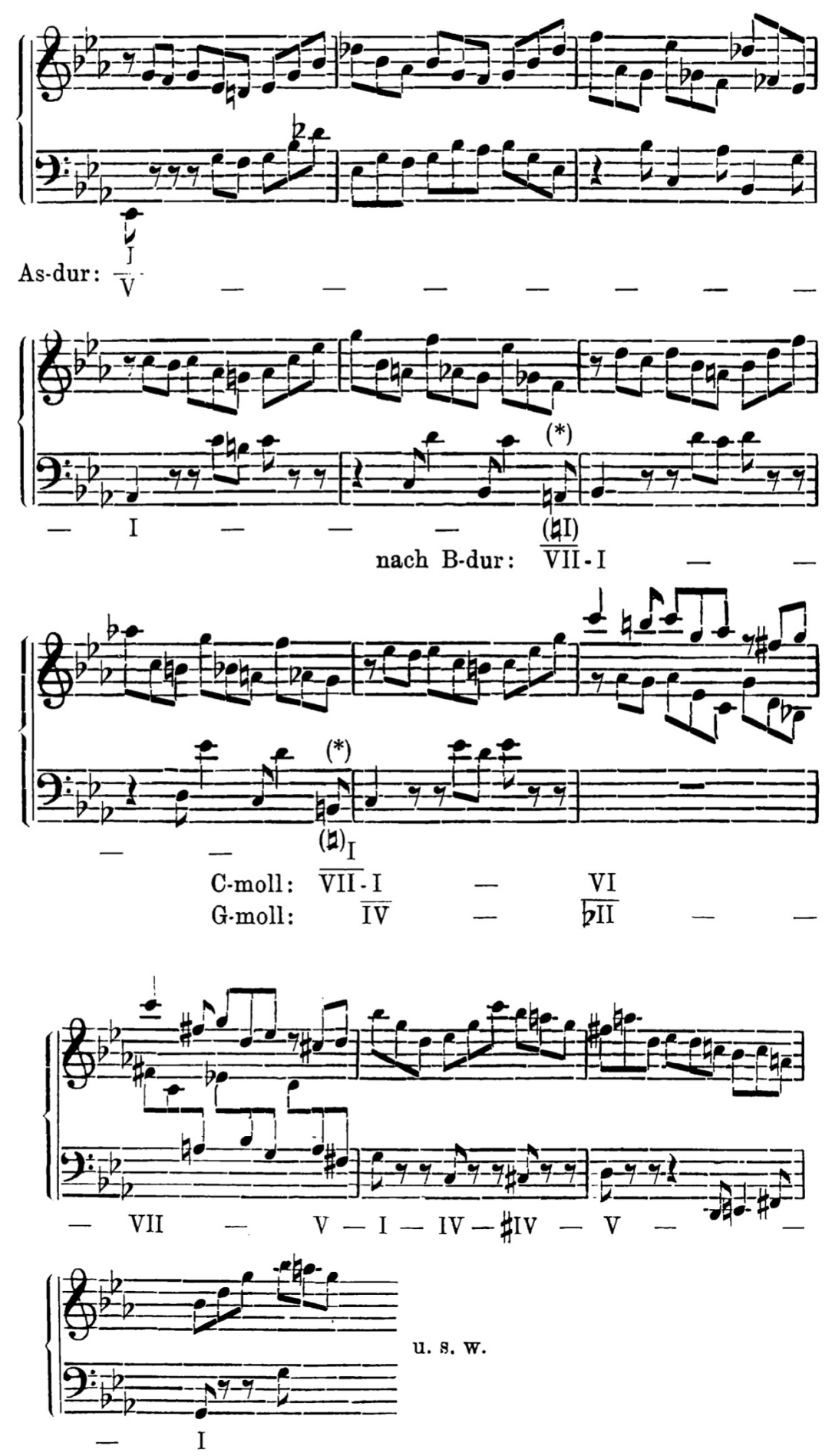

Figure 6: Schenker's analysis of Bach, Prelude in E major (WTC II), mm. 35-47 (Harmonielehre, pp. 439-440, Ex. 372).

Our perception of modulation is clearly different at each moment of Bach's score. In the case of "silent reinterpretation," the sense of the modulation is a retrospective one, and the use of chromatic elements like mixture, tonicization, and other forms of direct chromatic succession are auxiliary to the modulation itself. In the case of chromatic modulation, the chromatic element itself becomes the vehicle of perceptual change: "Modulation by chromatic change takes any harmonic phenomenon literally for what it is after the chromatic 
change has been applied to it, and it accepts its new modulatory meaning, while in the silent modulation, when combined with a chromatic element, one first has to detach this chromatic element (accounted for by its own process) from the root and only regard the modulation in the spirit of the exposed root" (SCHENKER, 1906, p.440-441). ${ }^{9}$

Finally, Schenker's third category of "enharmonic modulation" offers yet another way to perceive modulation. According to him, the advent of equal temperament led people to consider two notes with different spellings to share the same pitch-class, such as $E b$ and $D \#$. But, in enharmonic modulations, Schenker argued that the two tones still retain their own distinctive qualities. This possibility stems from the fact that each tone calls forth a different "diatonic sphere [...] so totally different that there is no connection whatsoever between the keys to which the two enharmonically exchanged tones of the triad belong" (SCHENKER, 1954 [1906], p.332). Figure 7 offers a perfect case in point: $\mathrm{mm}$. 177-186 from the Scherzo of Beethoven's String Quartet, Op. 59, no. 1. The passage modulates from B major to Gb major by reinterpreting the $A \#$ sonority in $m .183$ enharmonically as $B b$, thereby allowing the music to shift from III to I in Gb major (the $D \#$ in the second violin comes from mixture) ${ }^{10}$ Remarkably, Schenker did not regard the modulation enharmonically as a fifth motion from $B$ to $\mathrm{F} \otimes$, but considers $\mathrm{Gb}$ as entirely foreign to $\mathrm{B}$. Since the enharmonicism has already occurred at the $\mathrm{Bb}$ chord in $\mathrm{m}$. 183, the newly won key of Gb major calls forth its own set of diatonic relations that have nothing to do with the previous $B$ major.

9 This translation builds on but nevertheless substantially alters the one given by Elisabeth Mann-Borgese in Harmony (SCHENKER, 1954 [1906], p.331).

10 In m. 182, Beethoven already reinterprets the $D$ in the second violin as $E$, but this goes unmentioned by Schenker. 
373] Allegretto vivace e scherzando

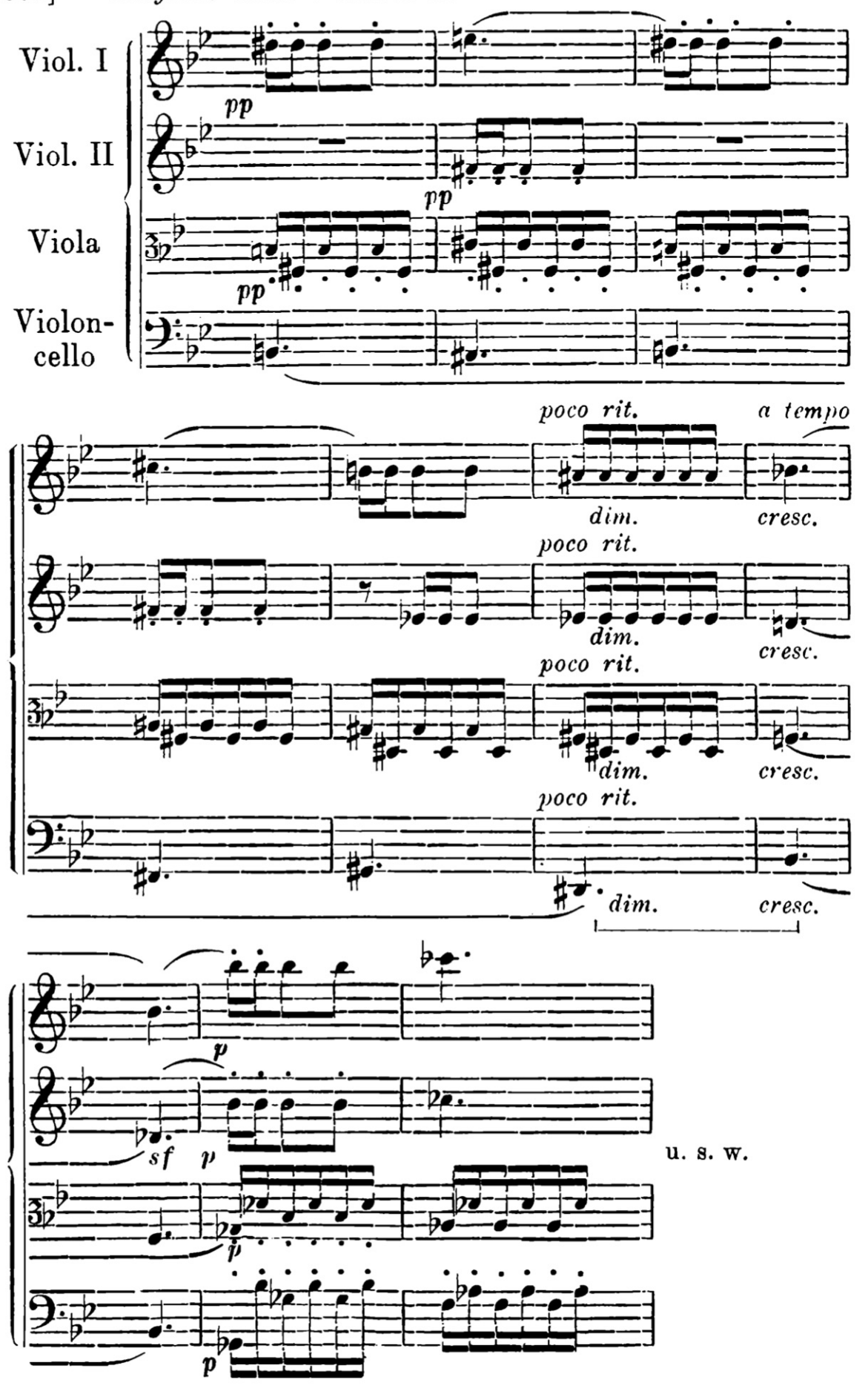

Figure 7: Schenker's analysis of Beethoven, String Quartet Op. 59 (Scherzo), mm. 177-186 (Harmonielehre, p. 442, Ex. 373).

Though he didn't explain his decision to modulate around the enharmonic relation A $\#$ $=\mathrm{B} b$, Schenker did note that enharmonic modulations do not merely change the notation for sake of convenience (as is often the case); on the contrary, he believed that they reflect a perceptual shift from one diatonic realm to another: "[t]he difference between these two 
cases results quite clearly from the keys which only in the case of a real modulation take a different course from that permitted by the development up to that moment" (SCHENKER, 1954 [1906], p.334). The question is this: at what point and at what level does such a shift take place?

The foregoing remarks have described the perceptual basis of Schenker's views of modulation. While Schenker is often credited with or rather, accused of, having eschewed modulation in his theory of the Ursatz, he actually regarded it as an essential feature of the surface and a vital component of "tonality." ${ }^{11}$ Instead of abandoning the idea of modulation as suggested by Jonas, Schenker simply placed it where he thought it belonged: at the foreground. His analyses from Harmonielehre should not, therefore, be thought of as antithetical to his later work; rather, they represent a view of musical surfaces that required no further explanation. And, although he implicitly used the theory of Mehrdeutigkeit in Harmonielehre, and maintained the distinction between diatonic, chromatic, and enharmonic modulations, Schenker showed how that theory and those categories should be understood in terms of composing out essential harmonies (Stufen). To underscore this idea, he shunned the use of abstract harmonic progressions in Harmonielehre, preferring instead to cite examples from well-known musical compositions. We will see below how this perceptually-motivated, surface-oriented view of modulation might relate to a Schenkerian graphic analysis.

\section{A Theoretical Interlude: Schenker's Views Towards Key Relations}

Having confirmed that Schenker always recognizes the significance of modulation at least as a surface phenomenon, it seems reasonable to consider what particular secondary key areas are possible within a monotonal composition. His most comprehensive account of this issue appears in $\mathbf{0 1 6 0}$ of Harmonielehre: "An Overview of the Apparent Chromatic Keys in the Diatonic System" ("Übersicht der chromatischen Scheintonarten in der Diatonie") (SCHENKER, 1906, p.394-396). Here Schenker summarized his ideas in two charts. The first, given here as Figure 8, uses the concept of mixture (Mischung) to combine all degrees of the major and minor systems. In the case of $C$ major/minor, this amalgamation results in eleven potential key areas: $C, D b, D, E b, E, F, G, A b, A, B b$, and $B$. By referring to the mixed third, sixth, and seventh degrees with a single Roman numeral, Figure 8 shows that combined systems still have only seven degrees, but that the second, third, sixth, and seventh degrees each have two forms with different roots.

11 This point is further reinforced in SCHENKER, 1979 [1935], p.5. 


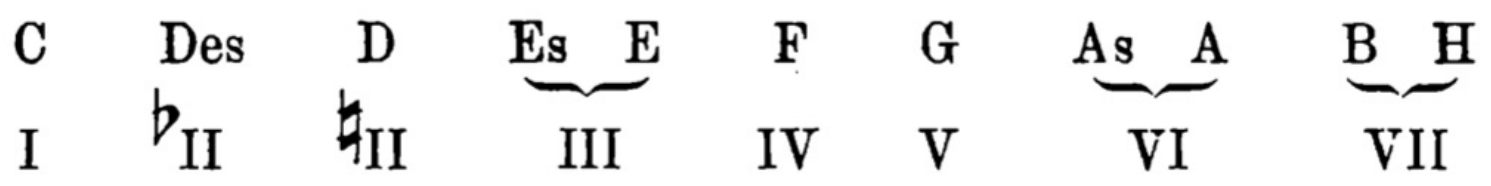

Figure 8: Schenker's potential key areas (Harmonielehre §160, p.395).

Schenker's list has a couple of striking features. Since minor keys include bll, the only way to express the supertonic as a subordinate key area is to lower the root. In the case of $\mathrm{C}$ minor, for example, the supertonic key will be Db major. Similarly, since ${ }^{\mathrm{major}} / \mathrm{minor}$ systems do not include to the roots \#IV or bV, modulations to keys a tritone away from the tonic can only be achieved indirectly, as, for example, IV of bII, III of blll, or VI of bVII. ${ }^{12}$ Schenker went further to claim that each degree can be expressed in major and minor forms: "Nothing stands in the way of projecting an "apparent" key chromatically on each of these degrees: in so doing, mixture, as an ever present compositional procedure, could penetrate even these pseudo-keys as well" (SCHENKER, 1906, p.395).

Adding these extra forms to his previous list, Schenker came up with the chart given in Figure 9 (SCHENKER, 1906, p.395). ${ }^{13}$ This figure, which Jonas cut from the English translation, shows that each degree can appear in several different forms: in $\mathrm{C}^{\text {major}} / \mathrm{minor}$, for example, the III degree can appear as Eb major and minor, as well as E major and minor. For Schenker, then, mixture refers to two slightly different processes: 1 ) interchanging roots and chord qualities of degree between the major and the minor systems, and 2) altering the quality of any triad from major to minor and vice versa.

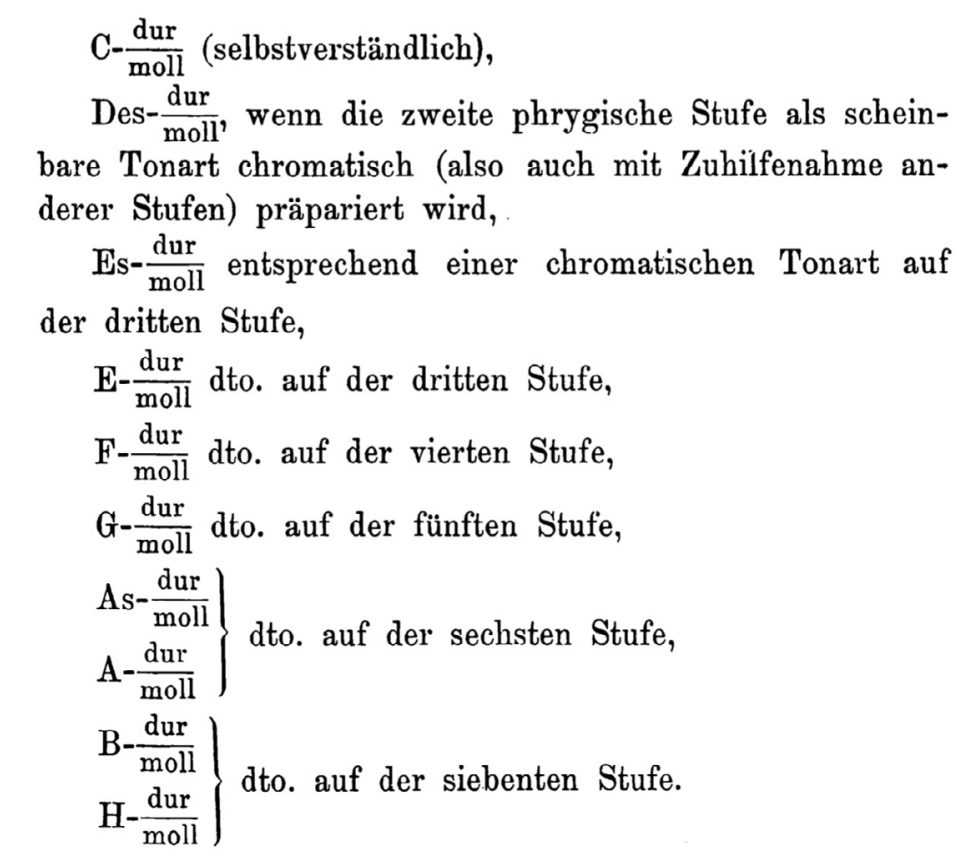

Figure 9: Schenker's theory of mixture (Harmonielehre §160, p.395).

12 See BROWN, M. et al, 1997.

13 Note that this chart should include "D dur/moll dto. auf der zweite Stufe," in accordance with Figure 8 above. 
In proposing that each degree can take diatonic and chromatic forms, Schenker presumed that chromatic degrees behave in the same ways as diatonic degrees:

In its chromatic state, the degree proves itself to be the same spiritual and higher unity that we have already defined for the diatonic form; the obligation to return to the diatonic system does not imply any restrictions as far as the duration of the chromatic degree is concerned; its duration remains variable just like that of the diatonic degree and varies from a minimum to the greatest conceivable maximum (SCHENKER 1906, p.388).

That said, chromatic degrees are always constrained by the rules of tonal voice leading. As Schenker explained in a critique of Wagner and Reger: "In sober but artistic terms, what is lacking is a proper progression of degrees [Stufengang]. In some cases this is lacking altogether; in others, the existing degrees [Stufen] are too wide, too highstrung, to support with any security the complexities of voice-leading and to cover them." (SCHENKER, 1954 [1906], p.174 [with slight alteration]).

Schenker was by no means the first music theorist to treat secondary keys as essential harmonies within the context of the global tonic, what he referred to as "Stufen der Tonalität als Tonarten." As Schachter has pointed out: "Schenker praises C.P.E. Bach for conceiving of 'keys' as prolonged Stufen, drawing this inference from Bach's referring to the goals of modulation as scale degrees in the main key" (SCHACHTER, 1987, p.299). Schachter also credited Rameau and Kirnberger for endorsing the same point of view, the latter even using "Roman numerals to indicate the scale degrees in the main key on which the new 'tonics' fall" (Ibid.).

And yet, Schachter rightly underscored the radical aspects of Schenkerian theory, especially Schenker's rejection of traditional notions of key relations. His rejection of relative keys makes perfect sense given that no two keys have the same notes, even those which same the same key signature. For example, $C$ major and $A$ minor may have no accidentals in their signatures, but authentic cadences in A minor require the leading tone $\mathrm{G} \#$ and often the raised submediant F\# as well. Since key signatures do not give an adequate account of what notes are required in a given key, the conventional distinction between closely- and distantly-related keys must be reconsidered as well. As Jonas explains: "How helpless and inartistic is conventional theory, which explains the absence of a key signature for A minor with reference to a "third relationship" to C major, and thus arrives at the notion of a 'relative' key-as if the borrowed g\# would not point sooner and more strongly to A major" (JONAS, 1982 [1934], p.29). In a footnote to his translation of Jonas's book, John Rothgeb makes the same point: "The concepts of 'relative major' and 'relative minor' are indeed foreign to Schenkerian thought. If, for example, an A-minor chord were tonicized within a work in C major, Schenker would explain it in any of several ways, depending upon the larger context: the $A$ bass might be a passing tone in a descending or ascending linear progression; it might be a neighboring tone to $\mathrm{V}$; or any of several other possibilities. He would never invoke an independent concept of 'relative' keys" (JONAS, 1982, p.29, n.27). 
Schenker's rejection of relative keys is, of course, striking because it put him at odds with other theorists of the day, including Arnold Schoenberg. Though Schoenberg also developed a theory of monotonality in texts such as Structural Functions of Harmony, his explanation of how subordinate keys might be related to a global tonic was very different from the one offered by Schenker in Harmonielehre (SCHOENBERG, 1969, p.19). Indeed, as shown in Figure 10, the eight vertical columns in Schoenberg's famous "Chart of the Regions" are produced by appealing to the concepts of relative and parallel keys. Take, for example, his chart of the regions for $\mathrm{C}$ major. The tonic $\mathrm{C}$ appears at the center of the chart in the fourth column. The relative minor key A minor (vi) then appears to the immediate left in the third column, whereas the parallel minor key $\mathrm{C}$ minor (I) appears to the immediate right in the fifth column. Schoenberg classified the regions immediately surrounding the tonic as close and directly related. Moving out from the center, the key of $A$ major (VI), the parallel of $A$ minor, occurs in the second column and the key of Eb major (bIII), the relative major of c minor, in the sixth column. Schoenberg classified these keys as close but indirect. As the columns proceed outwards they become increasingly remote from the tonic C.

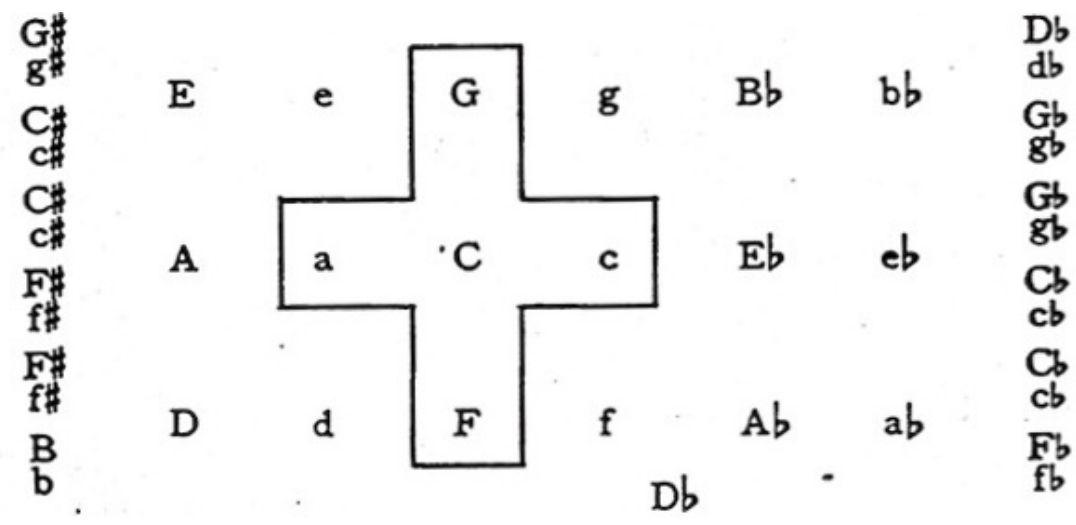

Figure 10: Schoenberg's Chart of Regions for C major (Structural Functions of Harmony, p.20).

For his part, Schenker addressed the idea of close and distant keys at the start of his essay, "Die Kunst der Improvisation," found in Das Meisterwerk in der Musik vol. 1 (1925). The essay, which focuses on C.P.E. Bach's guidelines for improvising preludes and fantasies from his Essay on the True Art of Playing Keyboard Instruments, begins by quoting Bach's excursus on key relations:

As is well known, the closest modulations in the major keys are to the fifth degree with the major third [V] and the sixth degree with the minor third [vi]. From minor keys, one moves first of all to the third degree with the major third [bIII] and to the fifth degree with the minor triad [v]. When one wishes to modulate to more distant keys, in the major keys this will be to the second and third degrees with the minor third [ii and iii] and to the fourth degree with the major triad [IV]. From minor keys, one modulates to the fourth degree with the minor third [iv] and to the sixth and seventh degrees with the major third [bVI and bVII]. All other keys are remote, and can be used with equal effect in a free fantasy, even though they stand at varying distances from the tonic (SCHENKER, 1994 [1925], p.4). 
Although Schenker did not cite any of C.P.E. Bach's sample modulations to remote keys, Figure 11 gives two examples from his treatise. These examples, which supposedly demonstrate how to modulate from $\mathrm{C}$ to $\mathrm{C} \#$ and from $\mathrm{C}$ to $\mathrm{F} \#$, are not dissimilar to those mentioned earlier by Reger and Jadassohn (compare for instance with Figures $1 a$ and b, above).

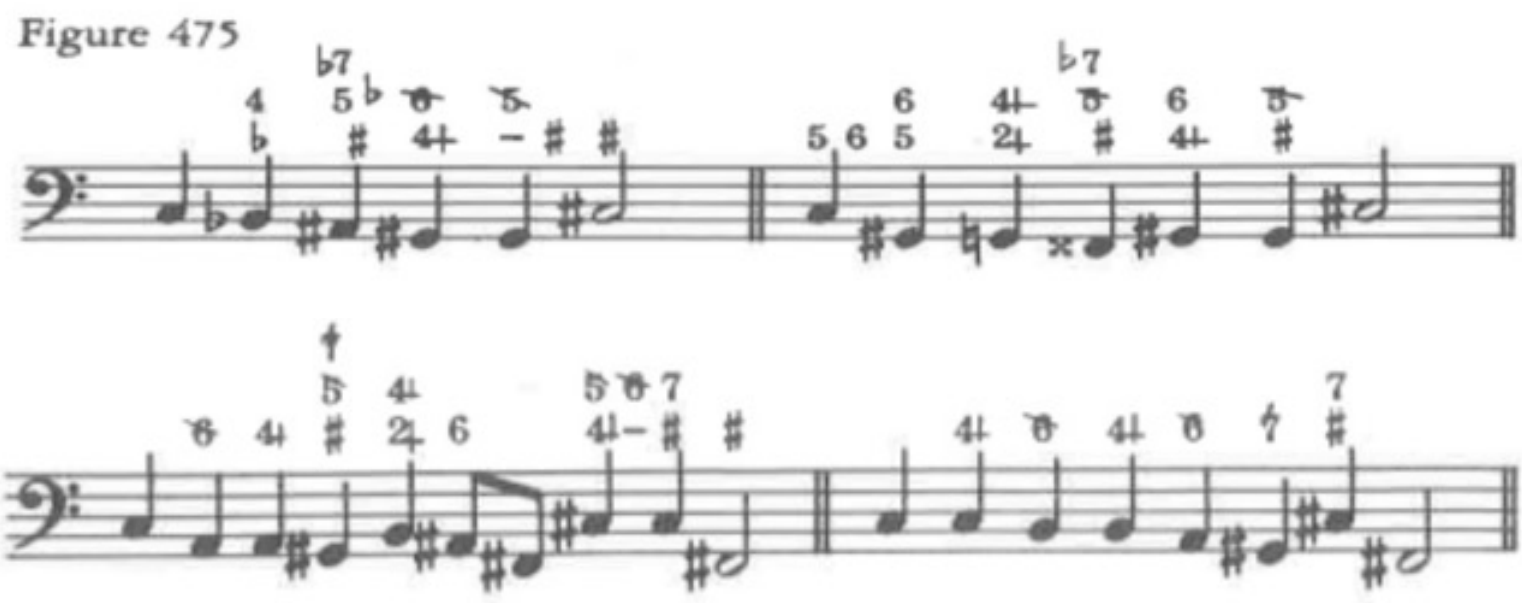

Figure 11: C.P.E. Bach's Examples of Modulation (Essay on the True Art of Playing Keyboard Instruments, Figure 475)

Indeed, after remarking on Bach's use of chromaticism, Schenker commented in a footnote: "Perceived from the thoroughly false basic ideas in Reger's Beiträge zur Modulationslehrecompare $507-11$ in Bach's chapter on the free fantasy; and Harmonielehre, p.445-what a discrepancy in the treatment of chromatic modulation, even on this single point!" (SCHENKER, 1994 [1925], p.4, n.6). Instead of criticizing C.P.E. Bach along the lines that he rebuked Reger, Schenker simply warned readers not to be "deceived by [C.P.E. Bach's] language": "by 'keys' [Tonarten] he describes a composing-out of scale degrees; in any case the term is not defined with systematic precision" (Ibid., p.4).

By linking the sequence of secondary keys to the principles of composing-out, Schenker also treated them in qualitatively the same ways as the progression of local chords:

The psychological nature of the progression of essential harmonies, which we have described so far in the context of form in the narrow sense, manifests itself in a marvelous and mysterious way also in the context of form in a wider sense-on the way from thematic complex to thematic complex, from group to group. In the form of clearly articulated secondary key areas (ausgeschrochene Tonarten) clearly stated earlier, we have simply the same progression of degrees, albeit at a superior level [now as essential harmonies] (SCHENKER, 1954 [1906], p.246 [with slight alteration]).

He added: "Thus for the sake of the bias towards extensive building of content, the natural progression of degrees is elevated correspondingly (SCHENKER, 1906, p.327; cf. SCHENKER, 1954, p.246)." Significantly, this progression of degrees is ultimately governed by the melodic 
nature of the bass line, something that ultimately rests on the principle of the triad: "Thus the bass, too, becomes melody, and its projection undergoes the influence of the harmonic principle no less than the melody; the bass, too, unfolds harmonic ideas; i.e., together with the other voices, it becomes a link in an unrolled harmonic concept" (SCHENKER, 1954 [1906], p.173).

Schenker offered a perfect illustration of what he had in mind in his response to C.P.E. Bach's own demonstration of preludizing at the end of his Essay on the True Art of Playing Keyboard Instruments. Bach began by presenting a simple plan written in figured-bass notation (see Figure 12a). According to this plan, the fantasy begins and ends with "long extensions on the tonic harmony" (at 1.) and includes "a modulation to the fifth [A] on which the performer remains for some time" (2.) followed by a move "toward E minor" at x. (BACH, 1974 [1759], p.442). Next, Figure 12b shows Schenker's voice-leading analysis of C.P.E. Bach's realization of this plan. This sketch shows not only how the arrival on the fifth $[A]$ is simply part of a larger arpeggiation of the tonic triad $D$ that extends from the beginning of the plan (1.) to the end of the second line (5.), but also how this goal tone arises from a stepwise descent in the bass from $D$ through $C, B$, and the leaping passing tone $E$ to $A$. Schenker's sketch also shows that the alleged move to $E$ helps to compose out the dominant harmony, which eventually resolves onto the tonic $D$ at (5.). Significantly, the latter is supported by a seventh $C$ in the bass, which allows Bach to tonicize IV at the start of the third line of the plan (6.). For his part, Felix Salzer has noted that the descent A, G, F, E in Schenker's 5-line Urlinie mirrors the implied descent D-C-Bb-A in Bach's original bass line (SALZER, 1976, p.162). ${ }^{14}$ According to Salzer, the beauty of Bach's realization is that it avoids creating parallel perfect $5^{\text {ths }}$ between the Urlinie and the bass line (A/D-G/C-F/B b-E/A) by elaborating, displacing, and chromatically inflecting the two lines. It also suggests that the function of the bass line may ultimately be motivic as well as melodic.

Schenker's decision to treat secondary keys in a monotonal composition in the same ways as chords in a harmonic progression does, however, have some interesting implications, especially for his later theories. Consider, for example, the various deep-middleground paradigms described by Schenker in Part II of Der freie Satz. Figure 13 gives a selection of options for a -line Urlinie that compose out the Baßbrechung by filling out the progression from I to V with intervening harmonies (SCHENKER, 1979 [1935], p.32-33). Many of these intervening harmonies are clearly surface chords, such as $\mathrm{I}^{6}(1 \mathrm{a}, 2 \mathrm{a}, 3 \mathrm{a}, 3 \mathrm{c}$, and $4 \mathrm{a})$ and IV ${ }^{7}$ $(2 c, 3 c$, and $5 a)$, but some might equally be secondary key areas, such as III\# (1b, 2b, 3b, $3 c$, and $4 a$ ) and II (2d and 6). Either way, 


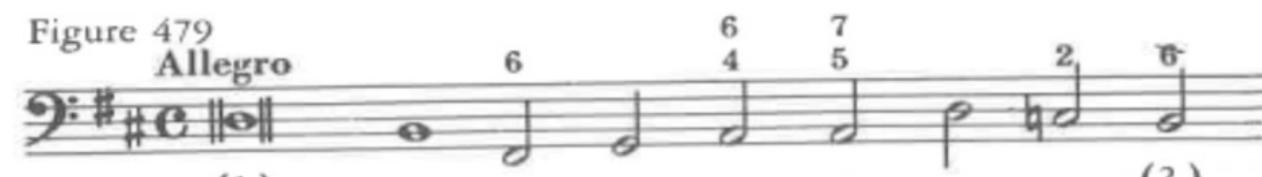

(1.)
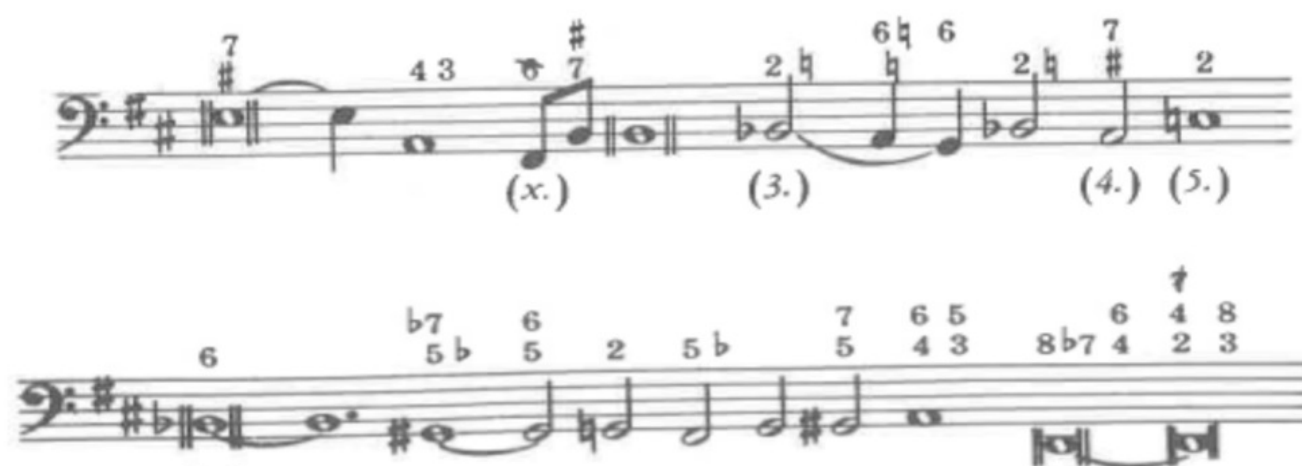

(6.)

Figure 12a: C.P.E. Bach's plan for a fantasy (Essay, Fig. 479).

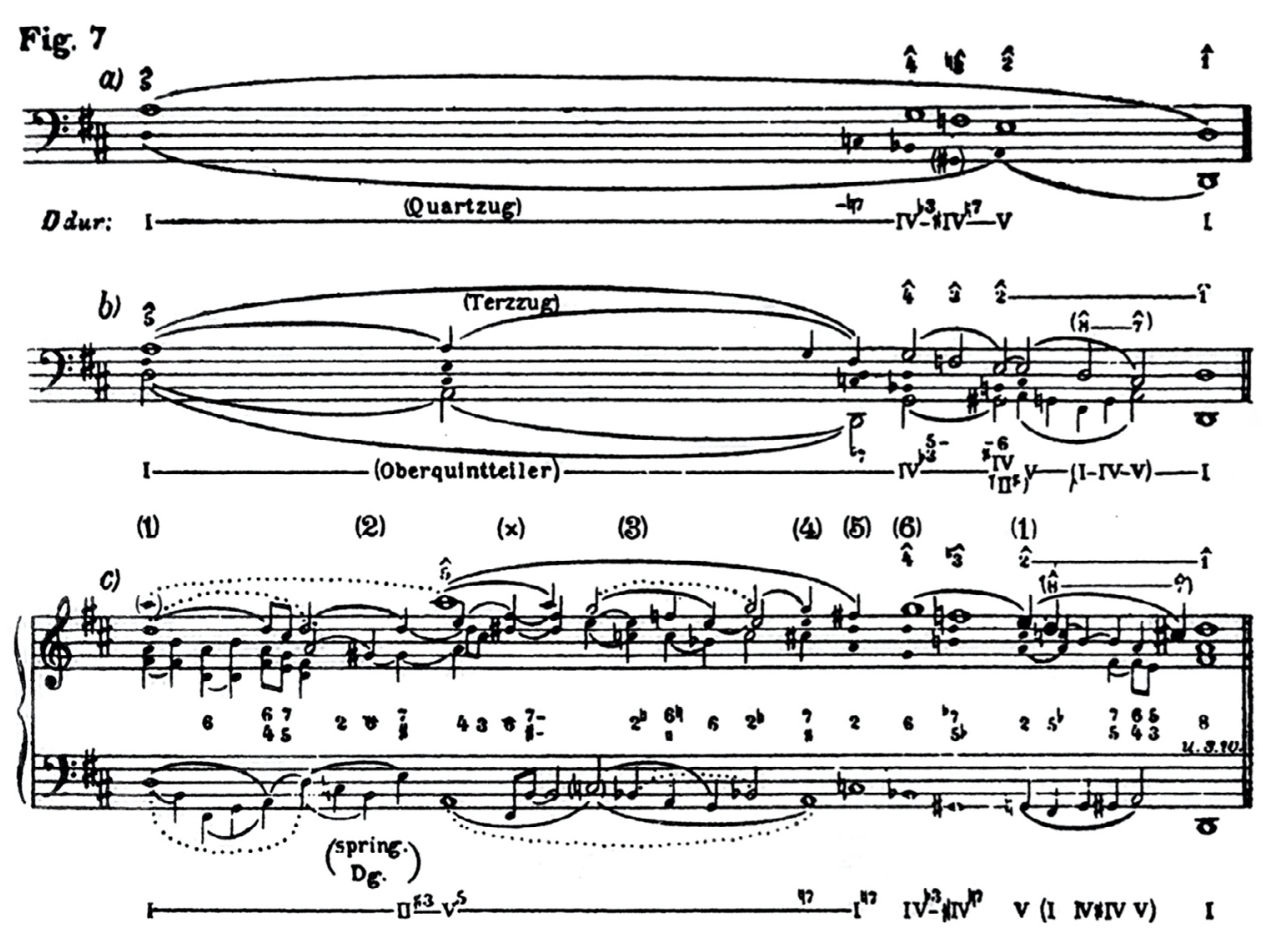

Figure 12b. Schenker's Analysis of C.P.E. Bach's Realization ("The art of improvisation," Fig. 7). 


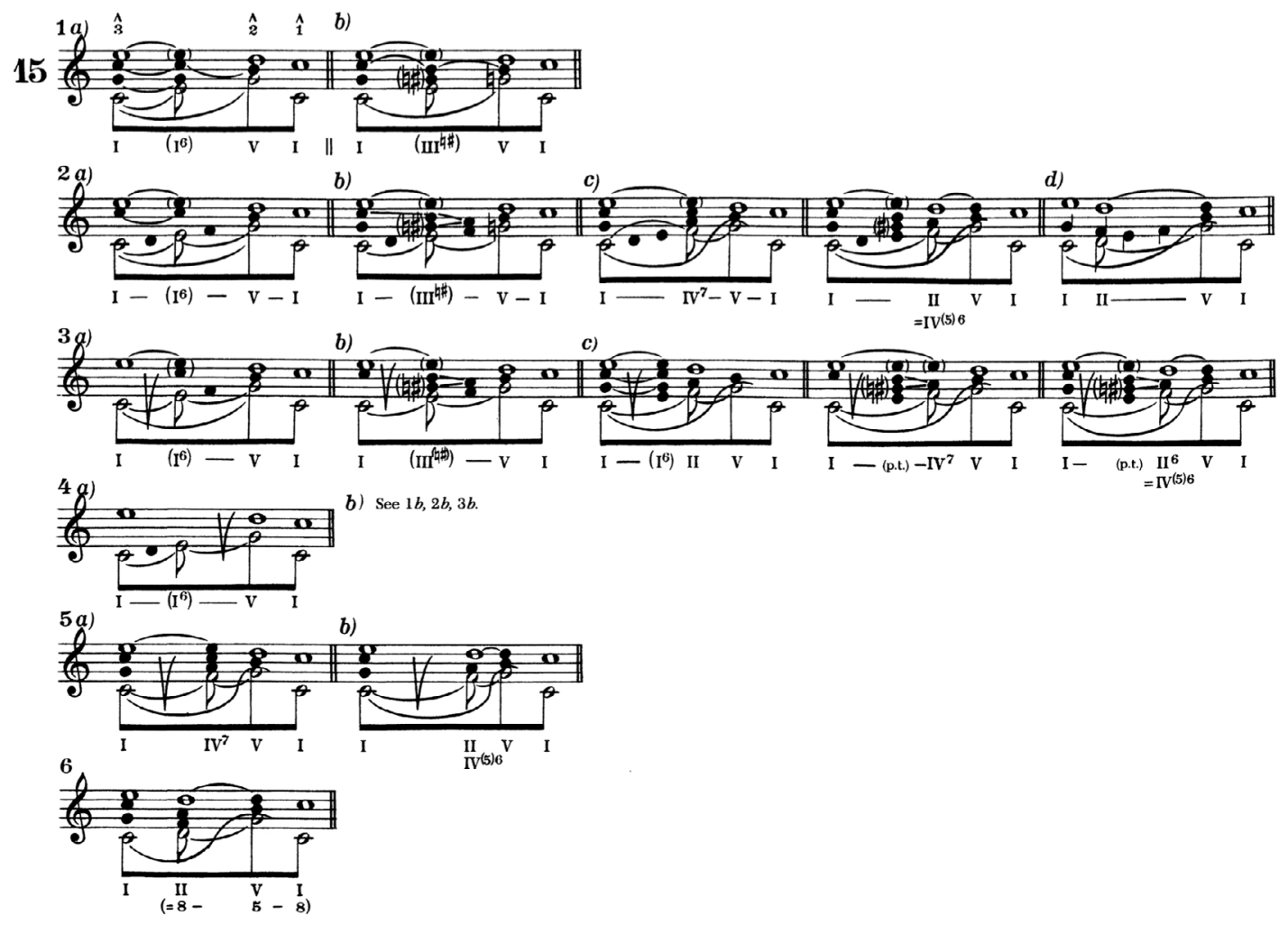

Figure 13: Schenker's Deep-Middleground Paradigms (Free Composition, Fig. 15).

Schenker's point is the same: whether the intervening harmony is a surface chord or a secondary key, it will arise contrapuntally from composing out the progressions from I to V and will be constrained by the same rules of tonal voice leading.

Given that the sequence of secondary keys in a monotonal composition is inextricably bound to the principles of composing-out, we are left to wonder how many different secondary keys can occur within the context of a monotonal composition. Contrary to Schenker's claim that conventional theory often invokes an "absurd abundance" of secondary keys, Schachter has highlighted the fact that the number of possibilities can be very large indeed (SCHENKER, 1979 [1935], p.8). He showed, for example, how Schenker proposed in \$161 of Harmonielehre that the development section from Beethoven's Piano Sonata in Eb major Op. 7/1 projects six "real keys" arranged in the following sequence: "C minor, Ab major, $F$ minor, G minor, A minor, D minor" (SCHACHTER, 1987, p.300). ${ }^{15}$ Besides noting that these six keys appear in "a not very long development section," Schachter added "[b]ut the keys are really there, at least on the surface, and it required a fundamental change in the way we think about music-a change that Schenker himself was to bring about-before musicians could convincingly relate key changes in such passages to a larger tonal context (Ibid., p.302).

15 See also SCHENKER, 1954 [1906], p.299-300. It is worth noting, however, that Schenker contrasted the types of key changes that occur in development sections with those in the exposition and development. Whereas the former may "endanger the definiteness of the diatonic system," the latter do not (Ibid., p.300). 
Schachter's sketches of the passage (see Figure 14) show that Schenker's six keys "result from linear activity with a harmony (or a progression from harmonies), and that a governing diatonic structure, ultimately derived from the tonic triad, could unify such heterogeneous elements" (Ibid.). In particular, the first four keys-C minor, Ab major, $\mathrm{F}$ minor and $\mathrm{G}$ minorform a group that falls within the orbit of $\mathrm{C}$ minor. According to Schachter, they do not project "a clear progression in the key of $\mathrm{C}$ minor, but they do articulate "a chromaticized voice-exchange" between the $\mathrm{C}$ minor sonority in $\mathrm{m}$. 141ff and the augmented-sixth in $\mathrm{m}$. 162 (Ibid.). The latter anticipates, albeit obliquely, the tonicization of $D$ at the end of the development in mm. 179-181 and eventually serves as a "leading tone" to the global tonic Eb, which returns at the start of the recapitulation in $\mathrm{m}$. 189. In other words, "the 'keys' that begin and end the development $-\mathrm{C}$ minor and $\mathrm{D}$ minor-crystallize around the notes of a linear progression leading up from $\mathrm{V}$ to $\mathrm{I}$. The other 'keys' serve either to extend the $\mathrm{C}$ minor chord (not key) at the beginning of the development or to lead into the D minor at the end" (Ibid.).

\section{Beethoven, Two Preludes "Through All Major Keys," Op. 39}

Schachter's basic point is certainly well taken, but it is important to stress that the number of surface modulations can be considerably more than six. Indeed prior to completing the first movement of Op. 7/1, Beethoven himself had composed two preludes in $\mathrm{C}$ major (Op. 39) for piano or organ that modulate "through all twelve major keys." First published in 1803/1804, these preludes actually date from 1789 while Beethoven was studying with Christian Gottlob Neefe in Bonn. ${ }^{16}$ From a purely historical perspective, the pieces stand out for a couple of reasons.

16 Although the autograph is lost, a manuscript copy (Berlin, Deutsche Staatsbibliothek, Ms. Artaria 128) includes corrections by Beethoven and is dated "1789 Von Ludwig van Beethoven." The last nine bars of the first prelude appear separately as Hess 310. See GREEN, 2003, p.179. 

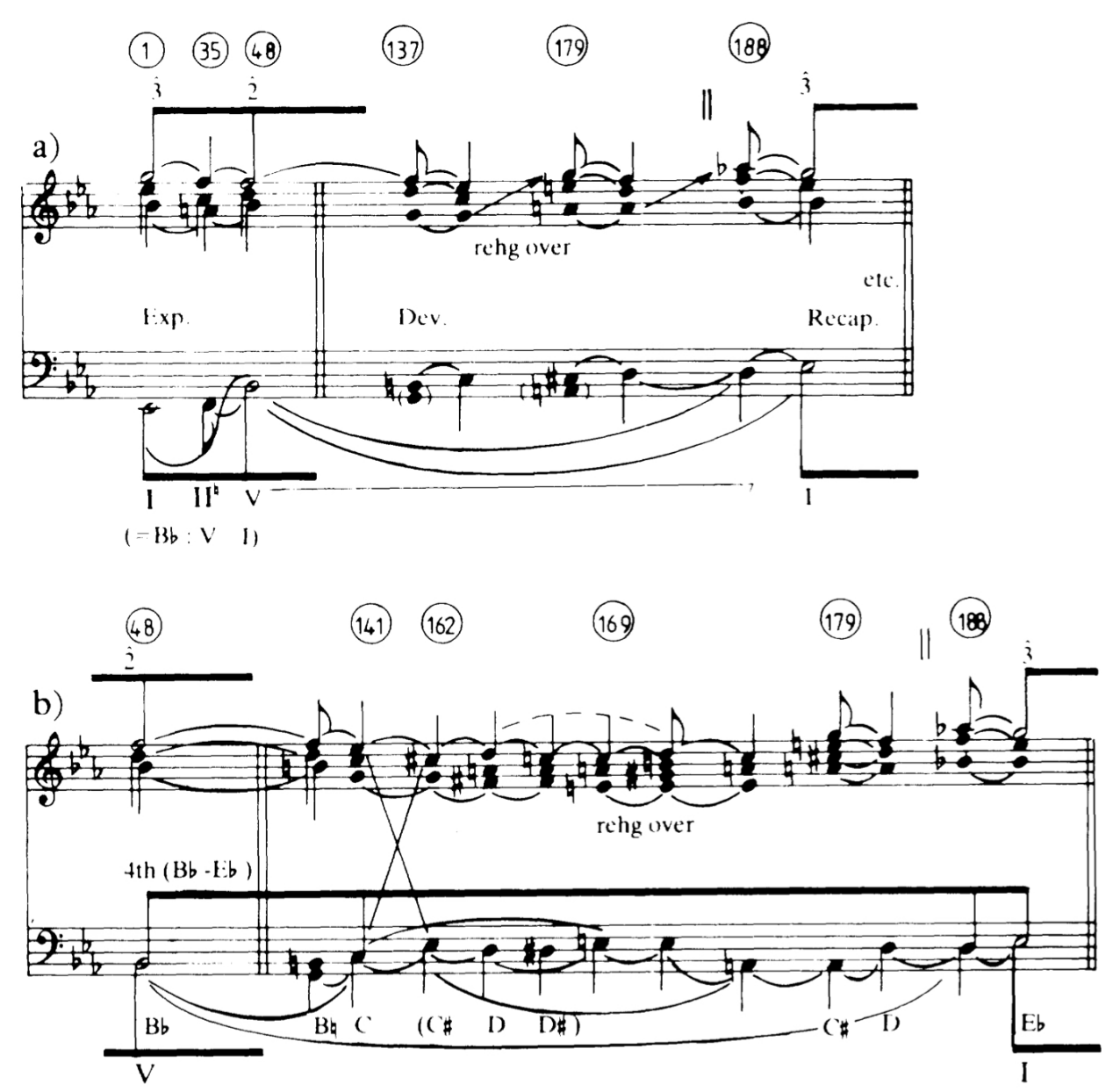

Figure 14: Schachter's analysis of Beethoven, Op. 7/1 (Schachter, "Analysis by Key," Ex. 5.10).

According to Maynard Solomon, Beethoven completed them after a four-year period (1785-1789) during which he had "essentially abandoned his career as a composer" (SOLOMON, 1972, p.166). By describing the preludes as "[o]bviously exercises written for Neefe," Solomon suggests that Beethoven returned to his teacher with a newly found desire to cultivate his skill at composition (Ibid., p.171). Jan Swafford has since conjectured that the hiatus in Beethoven's studies may have been caused by Neefe's involvement in the Bonn lodge of the Bavarian illuminati (SWAFFORD, 2014). But even more revealing than this, Jan Caeyers has recently underscored the extent to which Neefe's teaching was influenced by that of C.P.E. Bach, who he regarded as the Originalgenie. Neefe's teaching proved so inspiring that Beethoven carried "a copy of [C.P.E. Bach's] Essay wherever he went, and advised his pupils to do the same" (CAEYERS, 2020, p.25). Finally, it is worth noting that Neefe even bequeathed us a Fantasia in F minor that modulates successively from F minor through an array of keysEb major (m. 48ff.), C minor, (m. 109ff.), F major (m. 153ff.), D minor (m. 175ff.), F major (m. 205ff.), and $\mathrm{Bb}$ major (m. 219ff.)-before returning to $\mathrm{F}$ minor ( $\mathrm{m}$. 377ff.) for a reprise and $\mathrm{F}$ major for a short coda. 
Even from a cursory examination, it is clear that Beethoven's Op. 39 preludes illustrate his debts to both C.P.E. Bach and Neefe. Most obviously, they encapsulate C.P.E. Bach's aforementioned guidelines for improvising preludes and fantasies. Those guidelines, which are summarized in Figure 15, propose that preludes might follow a simple plan: 1) begin and possibly end with a tonic pedal (Figures 15a-b); 2) precede the final tonic with a dominant pedal (15c-d); and 3) connect the opening tonic pedal to the dominant pedal by an ascending or descending scale in the bass $(15 \mathrm{e}-\mathrm{g})$. The strings of consecutive integers in each indicate that Bach preferred stepwise strings in the upper parts. The scales can be unadorned (15e), elaborated with chromatic passing tones (15f), or recomposed and reordered in more drastic ways $(15 \mathrm{~g})$.

In his first prelude, Beethoven followed Bach's recommendation to a tee, using pedal points, sequences, and stepwise linear progressions at every turn. Take, for example, the final dominant pedal, mm. 104-115 (see Figure 16). As the figured bass indicates, Beethoven specifically recalled the patterns given in Figure 15d, enhancing them with a chain of diminished seventh chords. As we will soon see, Bach's fondness for sequences and stepwise linear progressions had an equally powerful impact on Beethoven's music, especially as devices for modulating from one surface key to another.

As the title to the work suggests, those modulations proceed by rising fifths through all major keys. ${ }^{17}$ The first prelude, which is 124 measures long, runs through the cycle of fifths once and spends enough time in each key to give a sense of its nature, ascending to a climax in the middle and then returning to $C$ major. In contrast, the second prelude is just 76 measures long and cycles through every key twice, sometimes spending only a single measure in each key in an almost absurd desire to work out the modulatory scheme. Given its broader scope, imitative texture, heavier use of chromaticism, extended sequential passages, and more worked-out motivic material, it seems likely that Beethoven put more work into the first than into the second prelude. 
Opening/Closing Tonic Pedal, Intervening Dominant Pedals

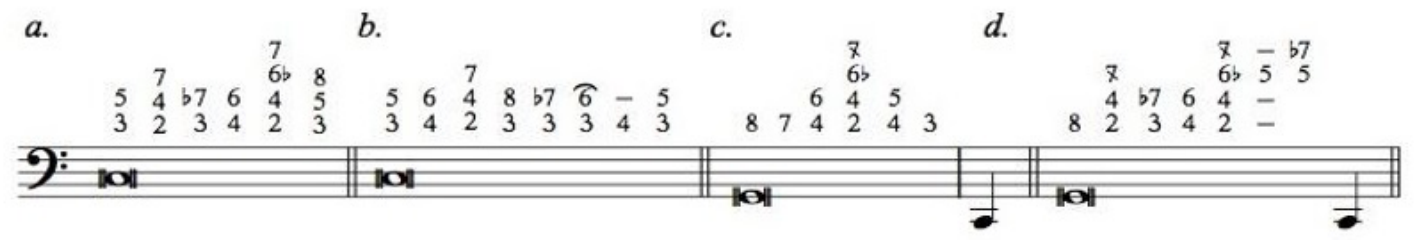

\section{Connecting Scales}

e. Unadorned

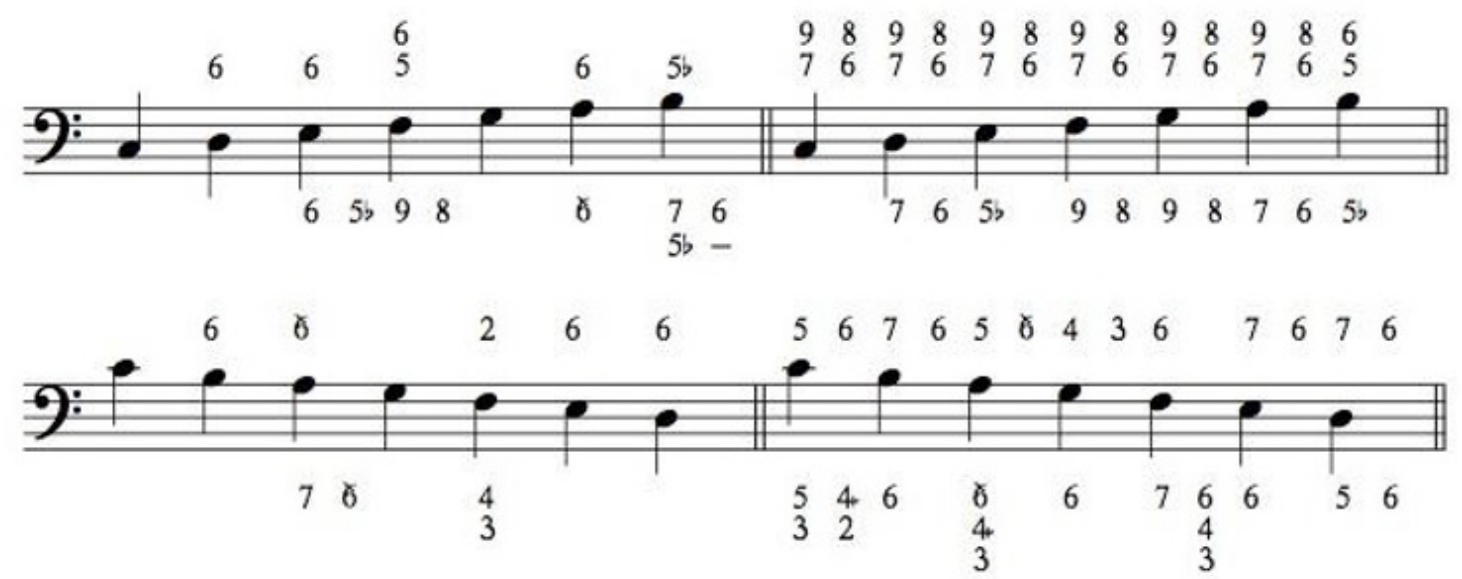

f. Elaborated with Chromatic Passing Tones
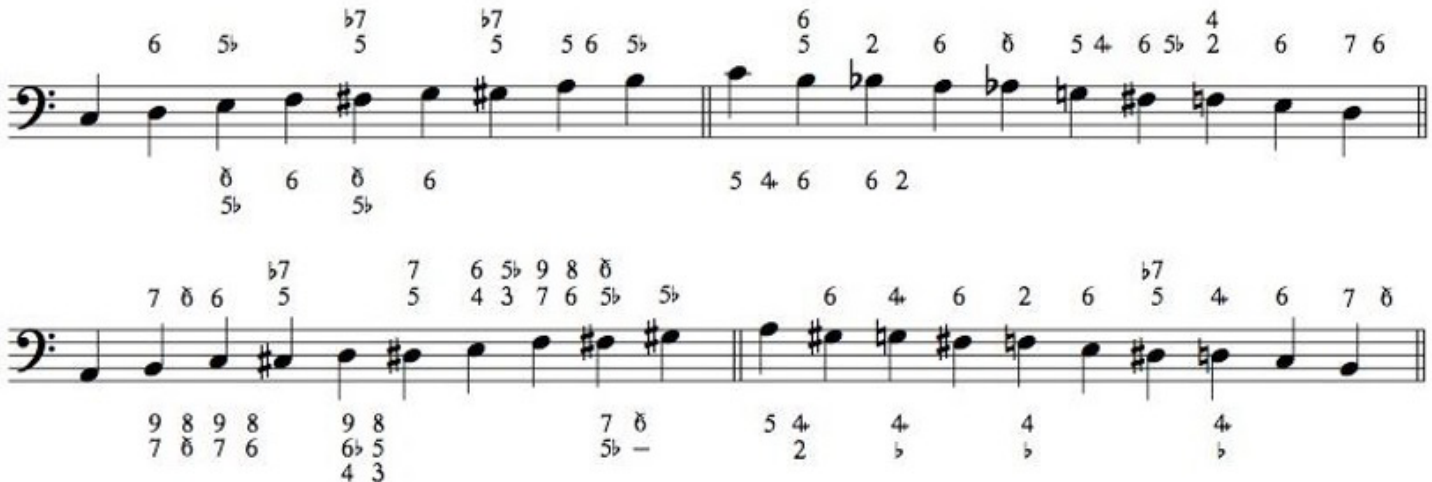

g. Recomposed and Reordered

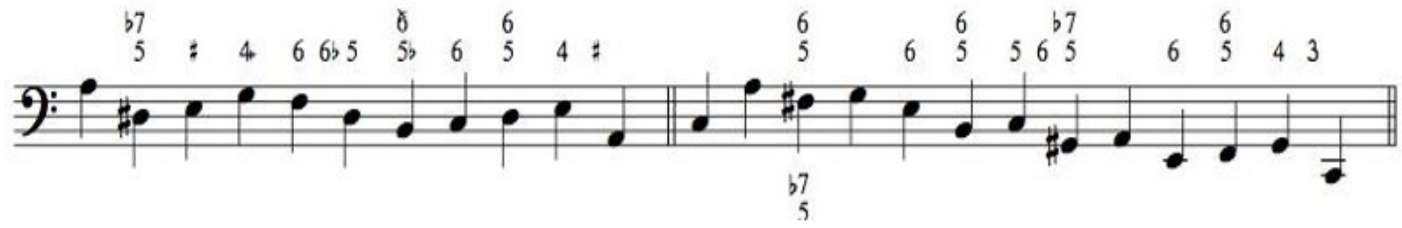

Figure 15: C.P.E. Bach's Plan for Composing a Simple Prelude. 

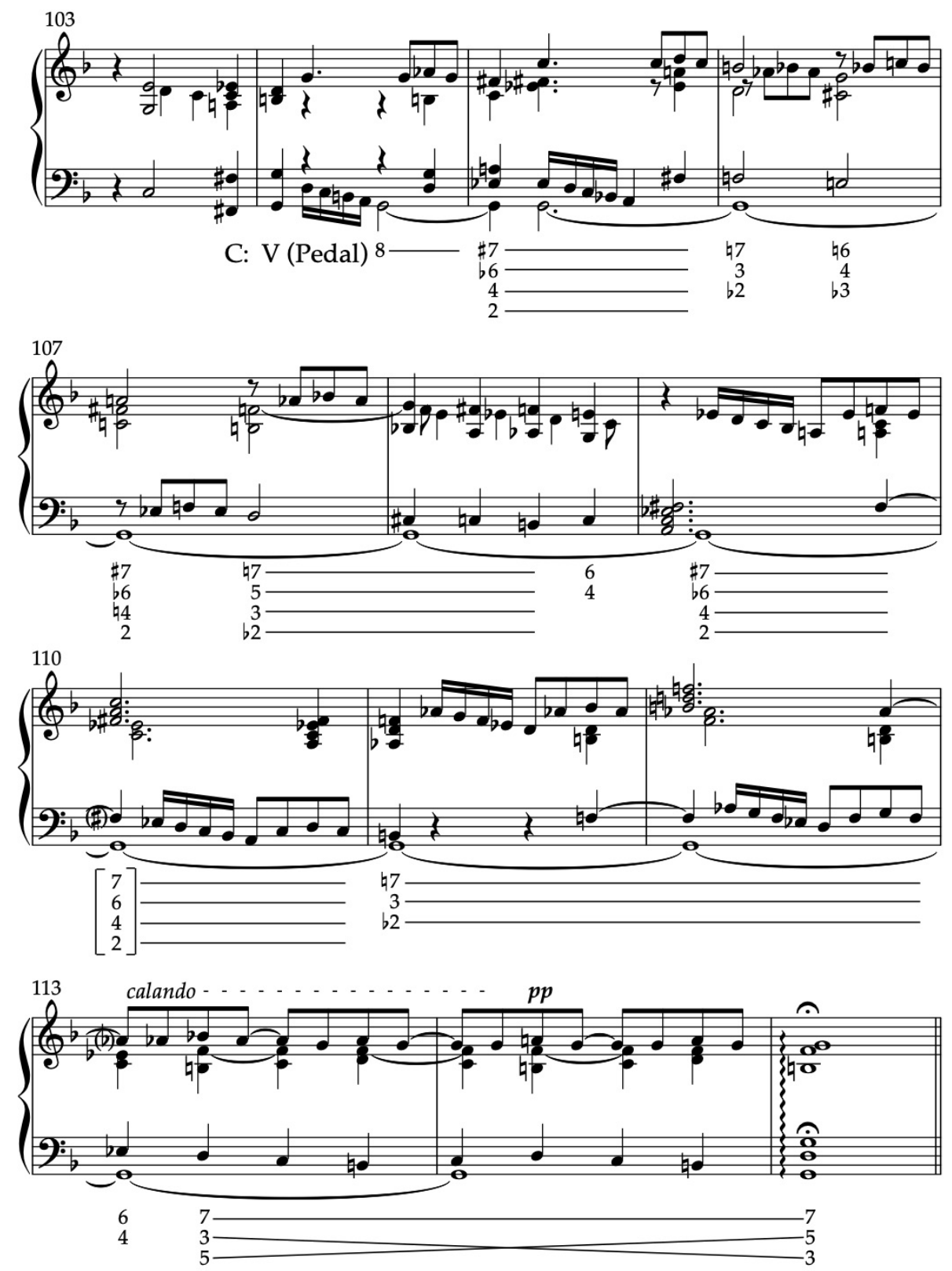

Figure 16: Beethoven, Op. 39/1, mm. 103-115 (with figured bass annotations).

The opening measures of each prelude illustrate some of the similarities and differences in Beethoven's approach. ${ }^{18}$ The opening of the second prelude, shown in Figure 17a, begins with a surface diatonic progression $I-V I-I I-V-I$ and a contrapuntal pattern between the tenor and soprano voices in which 6ths and 10ths interchange (making the pattern invertible at the octave). Behind this simple harmonic progression lies an even more fun-

18 Though score examples have been provided for certain passages from the Op. 39 preludes, the reader is strongly encouraged to consult the full score when examining the graphs below. 
damental element: an implied tonic pedal. This is indicated beneath the harmonic-contrapuntal analysis of Figure 17a and further reinforced graphically in Figure 17b. The latter Figure also divulges one of the main recurring linear progressions in both preludes, namely the third-span $\hat{5}-\hat{4}-\hat{3}$.

This progression is preceded by both an arpeggiation from $\hat{3}$ to $\hat{5}$ and (on a slightly lower level) an incomplete upper neighbor on $\hat{\sigma}$ ( $\mathrm{A}$, in this case). This progression is repeated verbatim an octave higher in $\mathrm{mm}$. 3-5, thus continuing the implied tonic pedal (we will see later how the implied pedal here becomes a literal one in a key modulatory passage in the first prelude). The first local modulatory move, from $C$ major to $G$ major, then takes place in $\mathrm{mm} .5-6$. As shown in Figure 17a, the initial tonic is reinterpreted as IV in the new key, from which a cadential progression in G major follows. Graphically speaking (Figure 17c), this implies a so-called "auxiliary cadence" (Hilfskadenz) whereby the local IV (supporting ) ultimately leads via $\mathrm{V}$ to I in the new key. The succession of parallel tenths remains intact, although now a local harmonic progression undergirds it. The alternate sketch in Figure $17 d$ shows an even more contrapuntally-oriented view of the passage. While the new harmonic progression is still evident on the surface, the correspondence with the opening progression is made evident through an implied pedal tone on $G$ (the opening $G 5 / 3$ chord is elided on account of the modulation). Most of the modulatory passages in the second prelude, as well as in the first, make use of this basic pattern.

While based on many of the same basic voice-leading principles, the first prelude is a far more sophisticated composition. Figure 18a provides an annotated score to the opening nine measures of the prelude. Like its companion, the prelude proceeds at the surface by upward fifth, with the first local modulation shifting from $\mathrm{C}$ major to $\mathrm{G}$ major. The texture, however, resembles that of a fugue, with the subject in the tonic being followed by answer in the dominant. Some might even identify the "head" of the subject in $\mathrm{m} .1$ and its "tail" in mm. 2-3 (postponed to beat two on

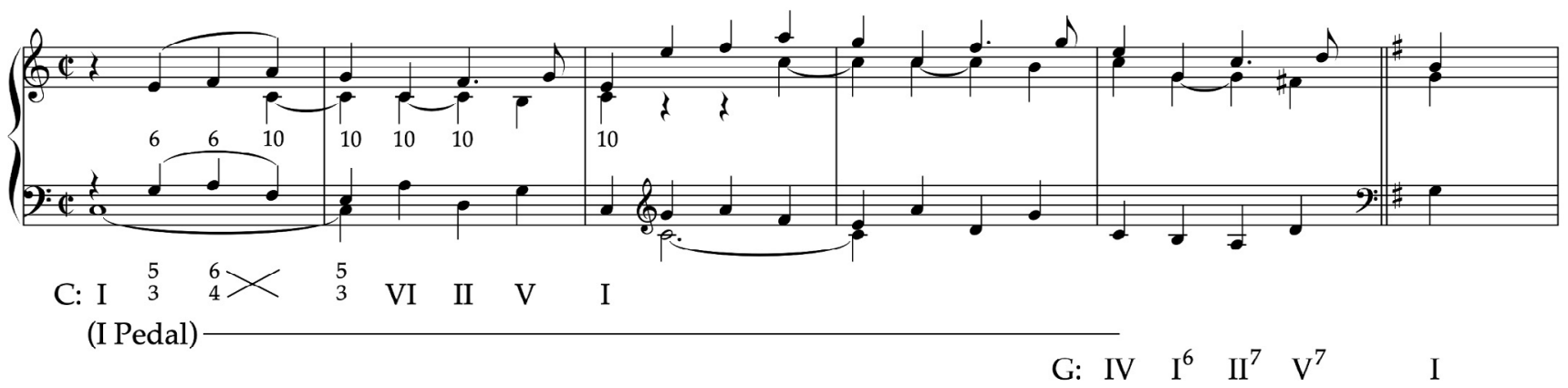

Figure 17a: Beethoven Op. 39/2, mm. 1-6 (score and harmonic analysis). 


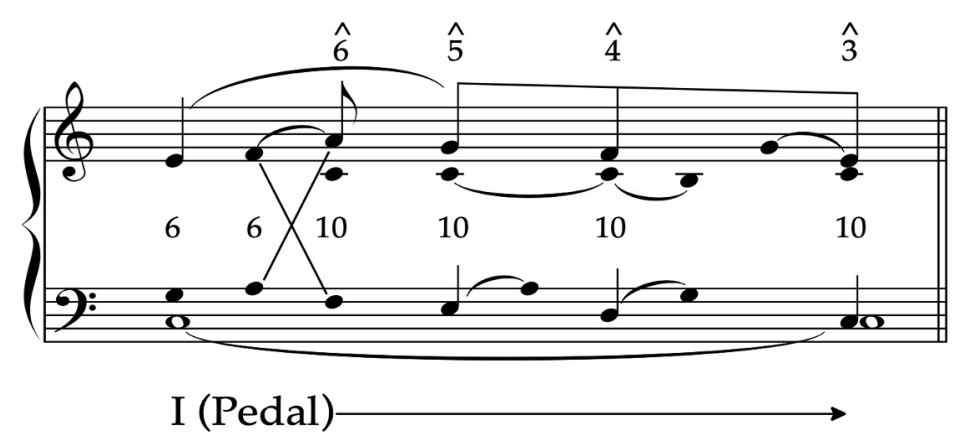

Figure 17b: sketch of Beethoven Op. 39/2, mm. 1-3.

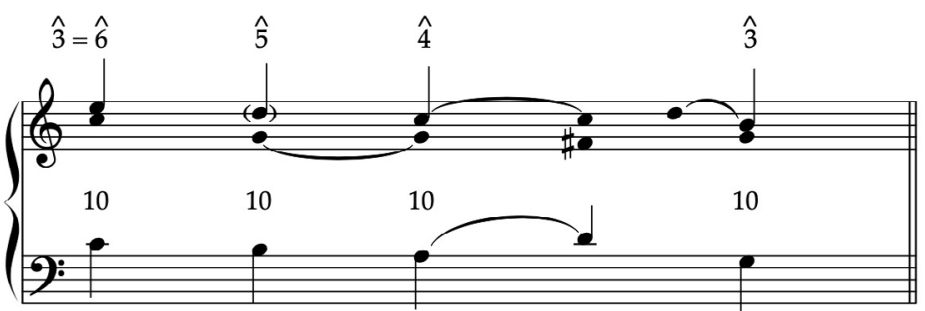

G: IV

$\mathrm{I}^{6}$

$\mathrm{V}_{3}^{7}=6$

I

Figure 17c: sketch of Beethoven Op. 39/2, mm. 5-6.

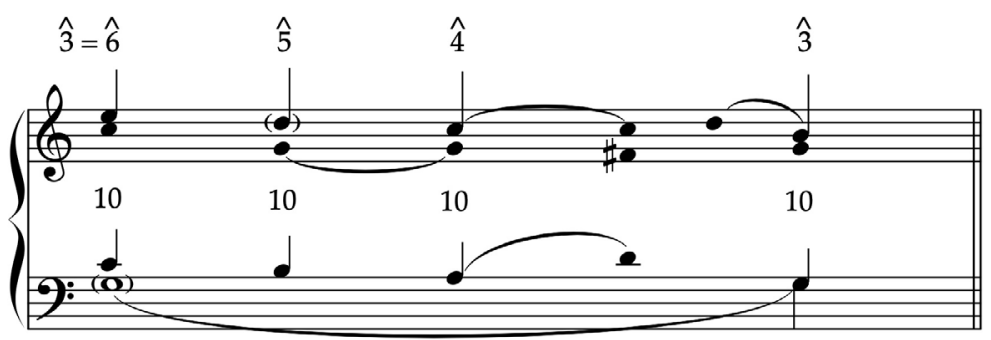

G: I (Pedal)

Figure 17d: alternate sketch of Beethoven Op. 39/2, mm. 5-6 (with pedal point).

account of the suspension). The answer, on the dominant, begins in stretto with the subject and presents a tonal variant of it (note the leap from $G$ to $C$ across $\mathrm{mm}$. 2-3). This "fugal subject" shares another feature with the opening melody of the second prelude: both ascend to before descending by step $\hat{5}-\hat{4}-\hat{3}$ (see Figure $18 b$ ). Figure $18 c$ then shows how, after the initial arpeggiation to $\hat{5}$, the stepwise descent $\hat{5}-\hat{4}-\hat{3}$ occurs on two levels: first, at the completion of the fugal subject; and second, on the downbeat of $\mathrm{m}$. 6 (the regaining of $\hat{5}$ at $\mathrm{m}$. 4 is similarly anticipated locally by a motion from an inner voice, $E-F-(F \#-) G$, an inversion of the descending third). Although a surface I-V-I progression accompanies the first descent, it is important to note that our reading treats the bass line contrapuntally: with an initial neighboring $\mathrm{C}-\mathrm{B}-\mathrm{C}$ progression (ultimately an inner voice) followed by a more 
structurally-determinant linear bass at mm. 5-6, C-B-(Bb-)A-(Bb-)B-C. This is the first of many places in which Beethoven uses a crucial linear pattern: $\hat{8}-b \hat{7}-\hat{6}-\natural \hat{7}-\hat{8}$ (see Figure 18a, bass, $\mathrm{mm} .3-6) .{ }^{19}$
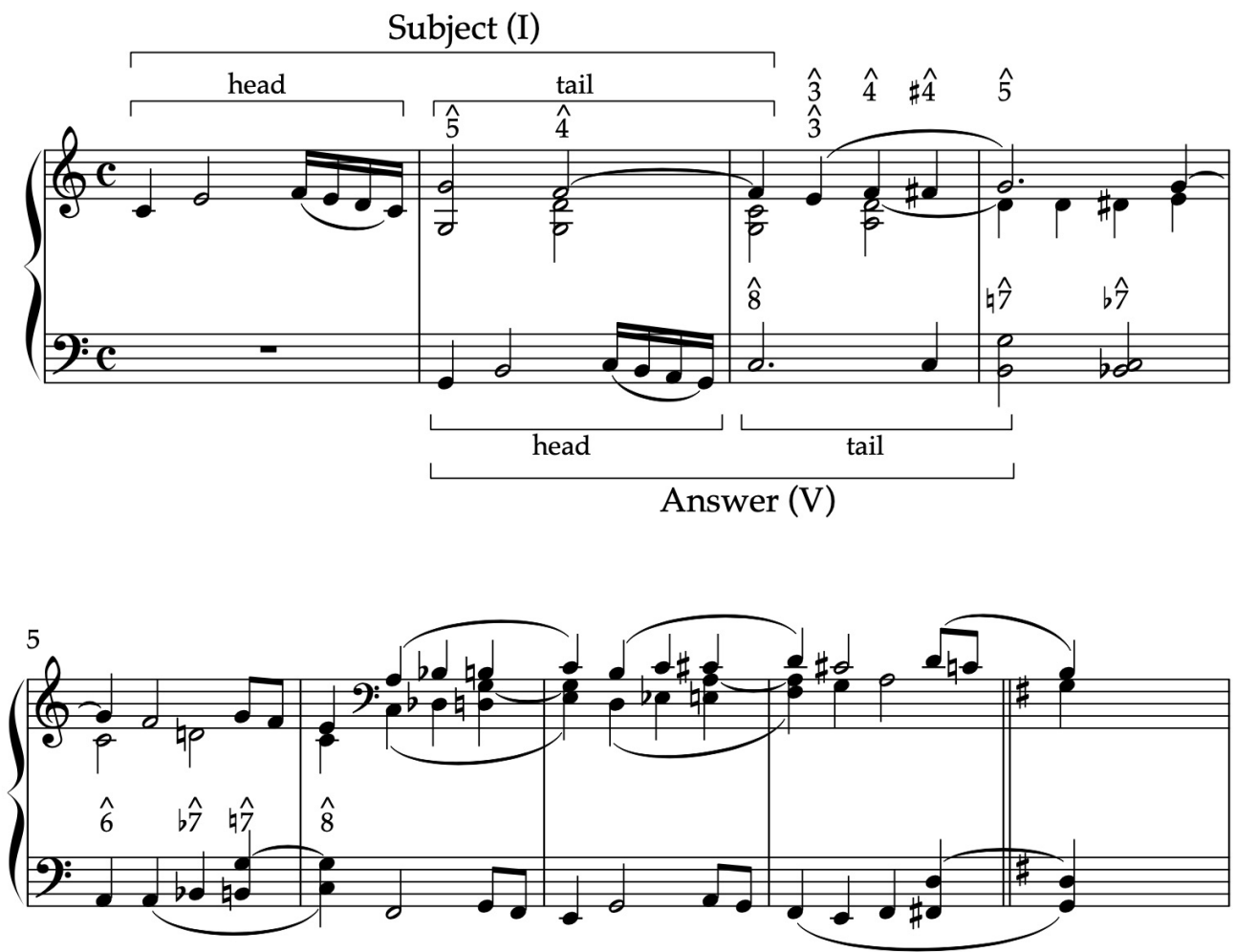

Figure 18a: Beethoven Op. 39/1, mm. 1-9

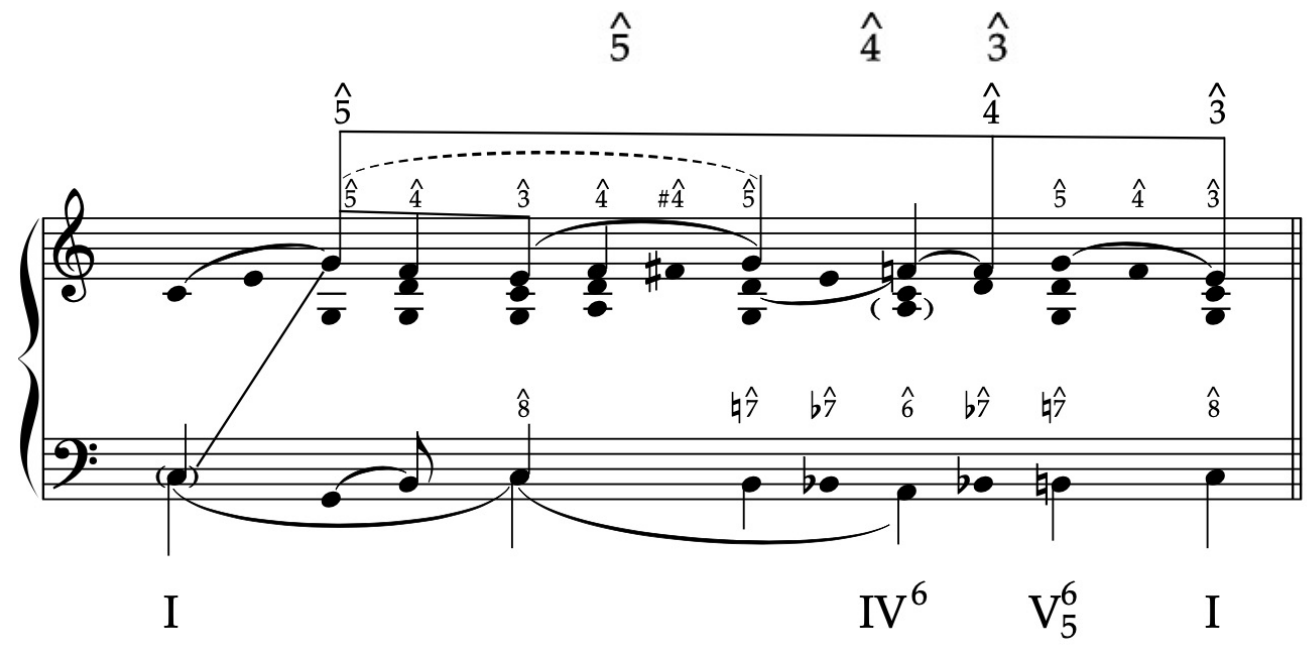

Figure 18c: Beethoven Op. 39/1, sketch of mm. 1-5.

19 Related to the $(\hat{6}-) \hat{5}-\hat{4}-\hat{3}$ and $\hat{8}-b \hat{7}-\hat{6}-4 \hat{7}-\hat{8}$ progressions of scale degrees are Robert Gjerdingen's "Prinner" and "Quiescenza" schemata (respectively). See GJERDINGEN, 2007, pp. $45 \mathrm{ff}$ and 181ff. The discussion that follows will show how these schemata can be incorporated into a wide variety of harmonic-contrapuntal progressions, as well as at various levels. 
As shown in Figure 19, the first "modulation," from $C$ to $G$ (mm. 6-9), follows a similar course to that of the second prelude. Once again, the governing tonic of $\mathrm{mm}$. 1-6 is reinterpreted locally as IV in the new key, from which ensues an auxiliary progression. Unlike the second prelude, however, the first prelude avoids local root-position progressions and achieves closure contrapuntally by resolving the leading tone upwards $(\hat{7}-\hat{8})$. This resolution is often extended by means of an ascending third in the bass $(\hat{6}-\hat{7}-\hat{8})$ or by a direct descending leap from from $\hat{4}$ (thus $\hat{4}-\hat{7}-\hat{8}$ ). The former case is particularly revealing in that, with the addition of a chromatic passing tone, a repetition of the melody of $\mathrm{mm} .3-4$ is formed, albeit with new tonal significance (that is, $\hat{3}-\hat{4}-\# \hat{4}-\hat{5}$ of the soprano in $\mathrm{mm}$. $3-4$ becomes $\hat{6}-\hat{7}-\# \hat{7}-\hat{8}$ of the bass across $\mathrm{mm}$. 7-9). To be sure, this pattern is also intimately related to $\hat{8}-b \hat{7}-\hat{\sigma}^{\wedge}-\natural \hat{7}-\hat{8}$ progression, albeit with the initial $\hat{8}-b \hat{7}$ elided (due of course to the nature of the auxiliary motion). Although the initial modulation in both preludes involves reinterpreting IV, that of the first prelude comes a more substantial composing-out of the Chord in $\mathrm{mm}$. 6-7 and the tonicization of a $\mathrm{D}$ minor chord in $\mathrm{m}$. 8. This prolongation is made possible by Beethoven's use of the chromatic ascending third motive, first as $A-B b-B-C$, then as $B-C-$ C\#-D) and expanded in the bass as E-F-F\#-G across $\mathrm{mm}$. 7-9.
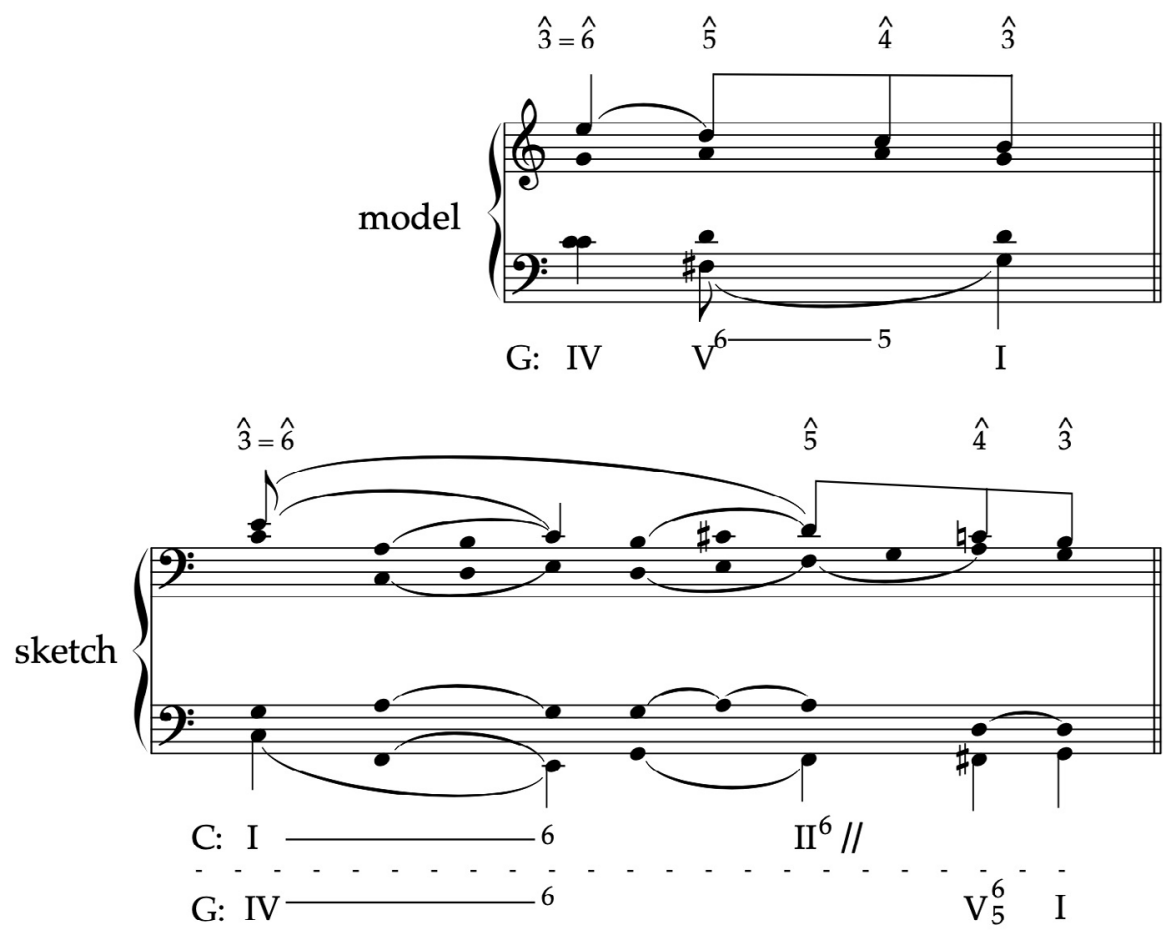

Figure 19: Beethoven Op. 39/1, model and sketch of mm. 6-9.

As the first prelude unfolds, Beethoven recycles many of the same contrapuntal and harmonic techniques to shift from one key to the next. Nevertheless, these techniques are employed in varying ways from section to section, sometimes allowing Beethoven to hint at other keys in the process, some by means of brief tonicization, others with a firmer sense of modulation. Certain passages, such as the modulation from G major to D major (mm. 13ff) make heavy use of imitation and sequential progressions. In mm. 13-21 (Figure 20), for instance, 
an underlying series of descending $6 / 3$ chords composes-out a G chord (now IV in D major), which begins with a quick 5-6 shift (G/B/D - G/B/E) and ends as a chord of mixture (where $\mathrm{B} \sharp$ becomes $\mathrm{B} b$ ) before progressing towards the cadence in $\mathrm{D}$. The figure begins with a basic contrapuntal model and works its way through two levels of analysis (labeled "a" and "b").
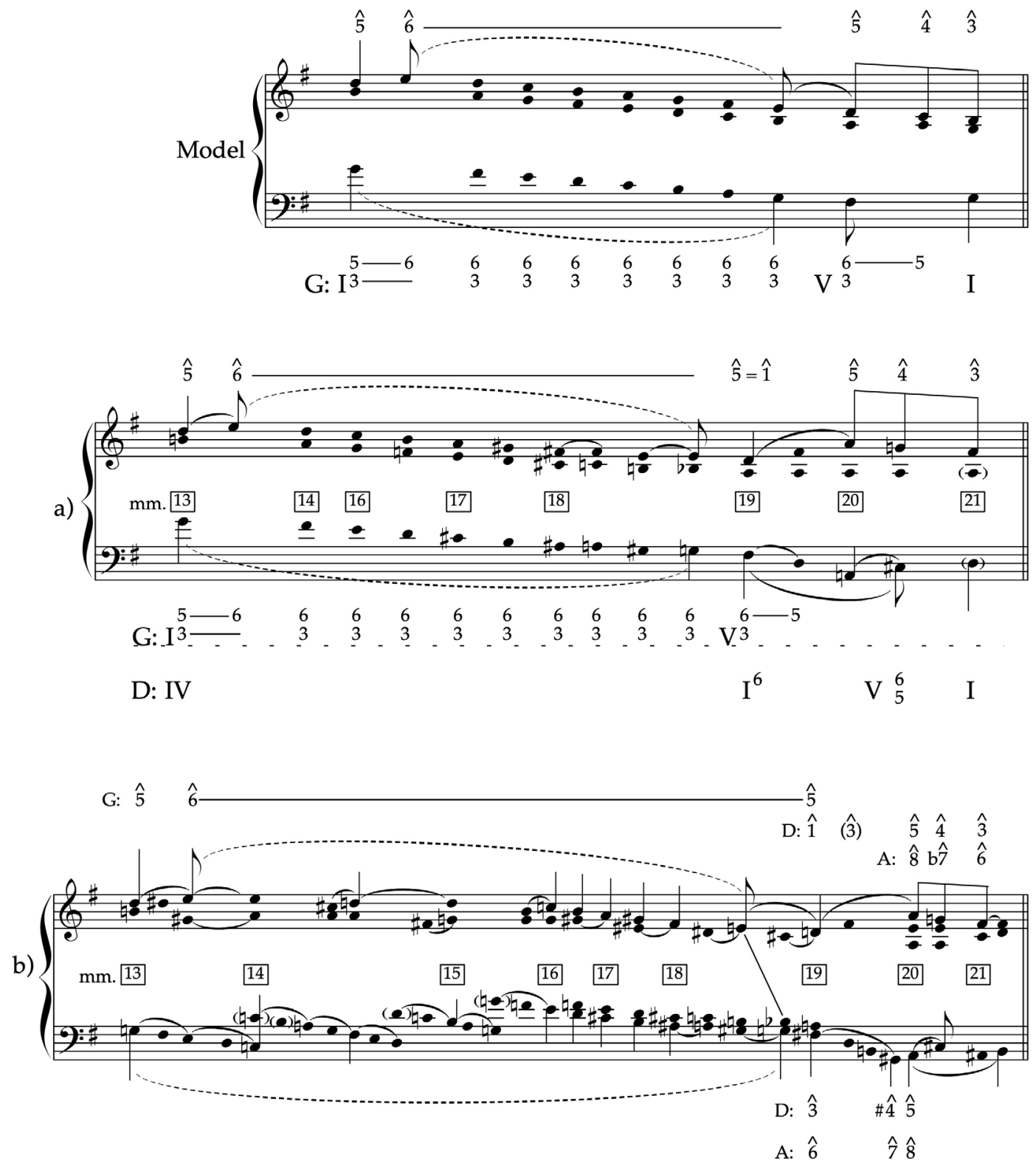

Figure 20: Beethoven Op. 39/1, mm. 13-21 (model and two levels).

The cadence in D, however, never transpires (hence the notes in brackets at the end of level "a"); the music lands instead on a deceptive cadence at m. 21 (shown at level "b"). At the same time, the preparatory $V$ of $D$ in $m .20$ initiates an ascending 5-6 progression, which at a deeper level composes out an octave A-A in the bass. The ascending 5-6 model and compositional working-out up to m. 28 is given in Figure 21. Although the A chord in $\mathrm{m}$. 20 functions locally as $\mathrm{V}$ of $\mathrm{D}$ major, it can also be interpreted retrospectively as the tonic of the upcoming key. The latter interpretation underscores two points: first, A major 
is achieved in the same way as $G$ major was previously, using $\hat{6}-\hat{7}-\hat{8}$ in the bass (at $m .24$ and again at $\mathrm{mm}$. 27-28); second, the upper voice of $\mathrm{mm}$. 20-21 once again uses the pattern $\hat{8}-\hat{7}-\hat{6}-\hat{7}-\hat{8}$. Many may continue to hear D major through $\mathrm{m} .21$ and possibly up to $\mathrm{m} .22$ (and understandably so, given the strong melodic reference to the patterns $\hat{5}-\hat{4}-\hat{3}$ and $\hat{3}-\hat{4}-\sharp \hat{4}-5)$, but this underscores the close interconnections between the various motives and the ease with which they can be perceived (and therefore analyzed) in keys a fifth apart. For the listener-analyst, the challenge lies in perceiving whether one key prevails over another and in deciding how a graphic analysis can support that perception or convey another one altogether. To a large extent, the nature of that analysis will depend on whether it privileges the harmonic or contrapuntal dimension.

The most significant moment in Beethoven's Op. 39 is surely the C\# major section from the first prelude ( $\mathrm{mm}$. 38ff): twenty-one measures long, it is easily the most elaborate part of both preludes. As Figures 22a-d demonstrate, the arrival in $\mathrm{C} \#$ is prepared by prior modulations to $E, B$, and $F \#$, each of which occurs over a short span of music: in just eleven measures Beethoven manages to cycle through four separate key areas. Furthermore, each modulation features a descending span $\hat{5}-\hat{4}-\hat{3}$ in the upper voice (often anticipated by an upper neighbor tone ) and the pattern $\hat{8}-4 \hat{7}-\hat{6}-\sharp \hat{7}-\hat{8}$ in an inner and/or lower voice. Figures $22 \mathrm{c}$ and $22 \mathrm{~d}$, which are direct transpositions of one another, stand out for their use of surface scales in the bass line. When $C \#$ emerges at $m$. 38, then, an important juncture has been reached, and $\hat{3}$ in that key $(E \#)$ firmly established (again, achieved through an anticipatory $\hat{5}-\hat{4}-\hat{3}$ linear progression, as shown in Figure 22d).
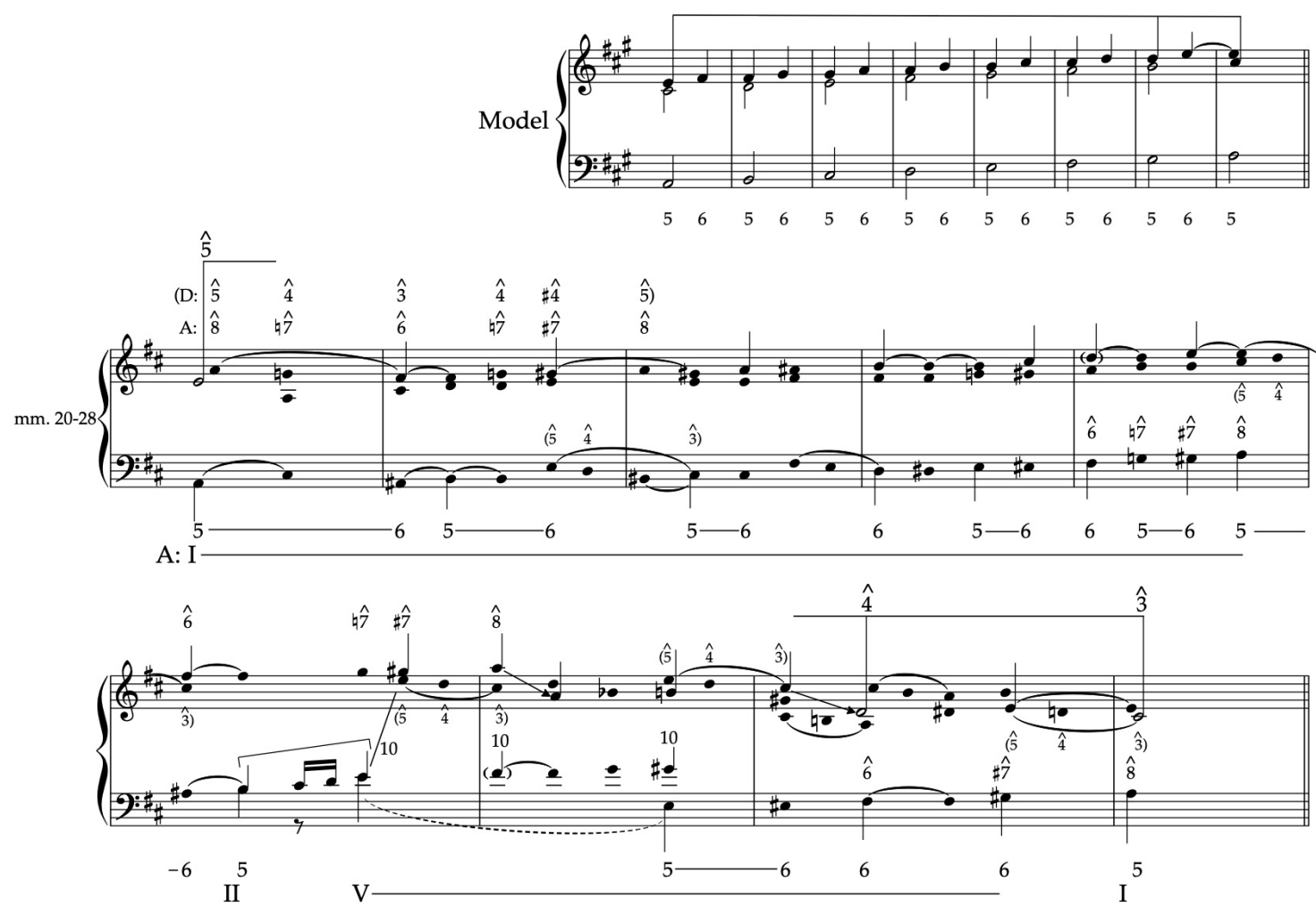

Figure 21: Beethoven Op. 39/1, mm. 20-28 (model and sketch). 


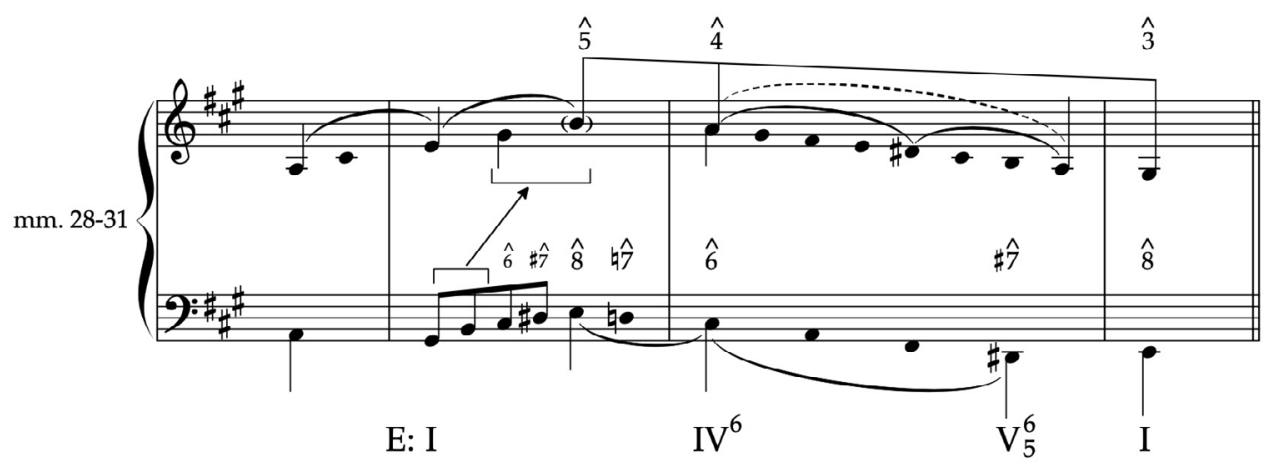

Figure 22a: Beethoven Op. 39/1, mm. 28-31 (modulation to E major).
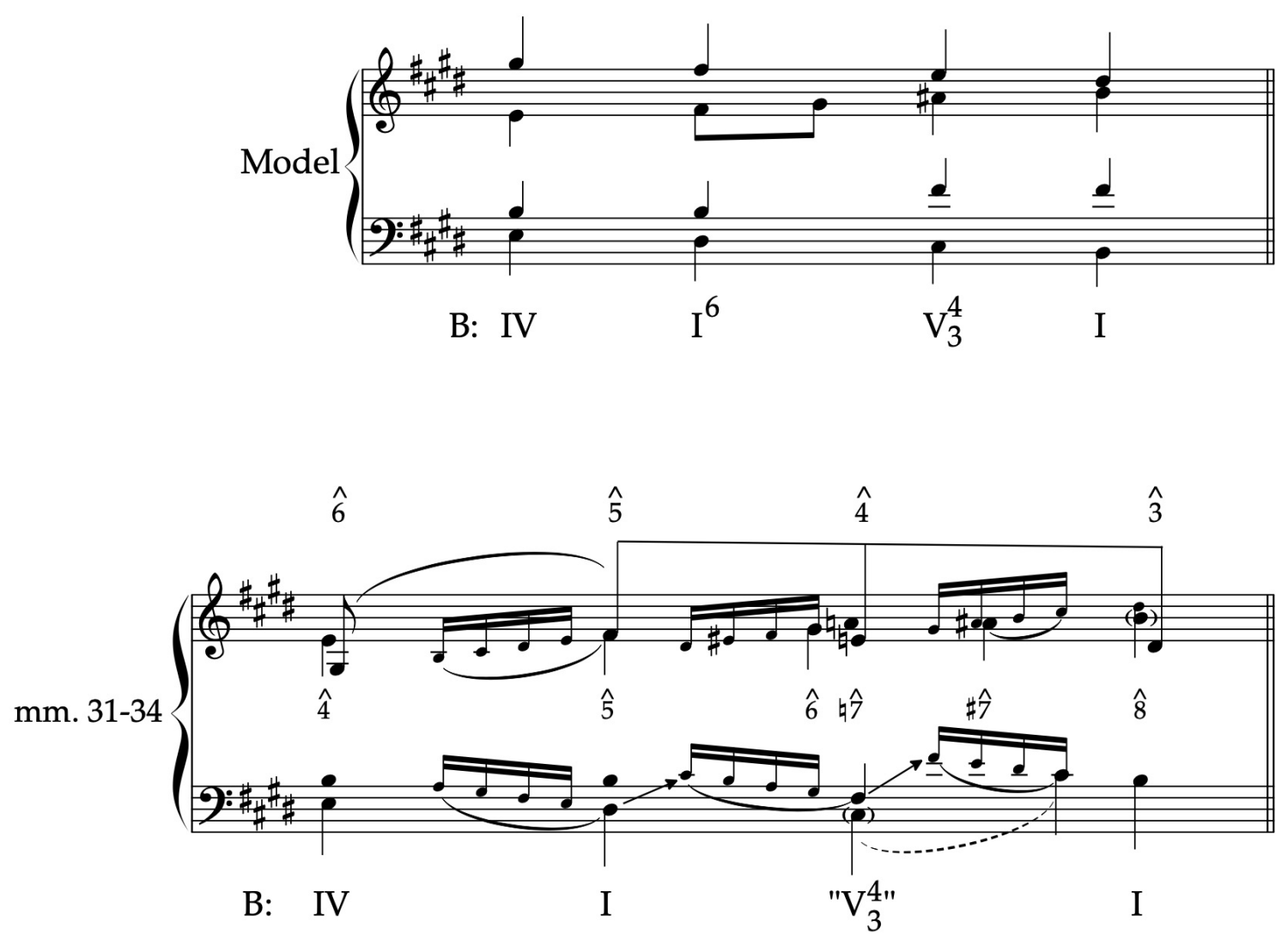

Figure 22b: Beethoven Op. 39/1, mm. 31-34 (modulation to B major). 


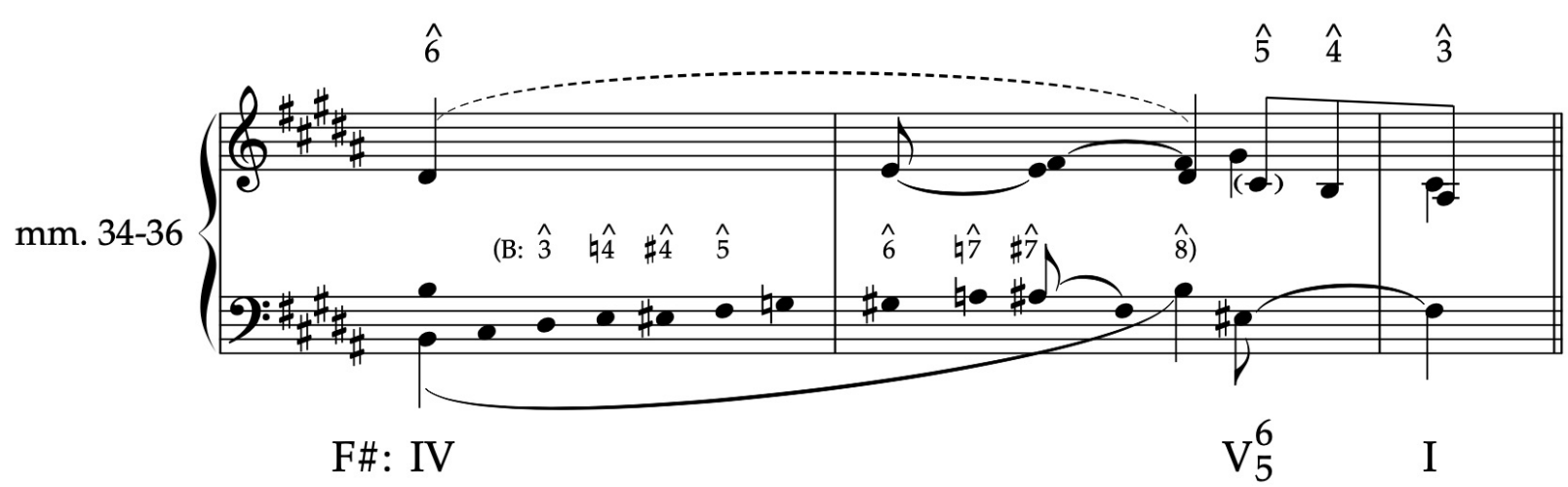

Figure 22c: Beethoven Op. 39/1, mm. 34-36 (modulation to F major)

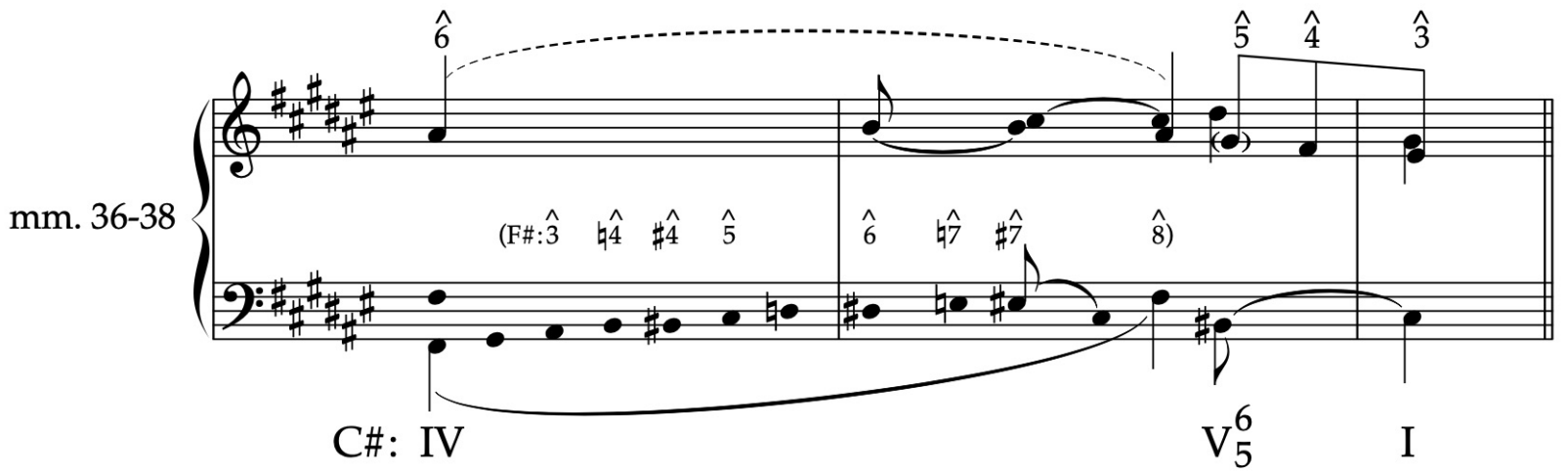

Figure 22d: Beethoven Op. 39/1, mm. 36-38 (modulation to C\# major).

Following the methods used by Schenker in Harmonielehre, Figures 23-24 provide two harmonic readings the $C \#$ major section, indicating the essential harmonies without inversions, but including any sevenths and mixtures (and using accidentals where appropriate). While Figure 23 looks in a detailed way at the local tonicizations and modulations found within these measures, Figure 24 takes a more bird's eye perspective of the music. That said, both figures clearly show that the $\mathrm{C} \#$ passage begins with the opening thematic material of the second prelude and a (now more literal) pedal tone (compare with Figure 17a). As shown in the score in Figure 23 and graphed in Figure 25, the pedal point on a local tonic $C \#$ undergirds a contrapuntal progression using the by-now familiar $\hat{8}-4 \hat{7}-\hat{6}-\sharp \hat{7}-\hat{8}-$ contrapuntal pattern $(C \#-B-A \#-B \#-C \#)$ at the start of the passage. Locally, these figures imply a progression I-V7/IV-IV-V-I. Beethoven makes use of the progression no less than four times: twice over the literal pedal point $(\mathrm{mm} .38-40)$, and twice by restacking the voices to "invert" the chords ( $\mathrm{mm}$. 40-42). Figure 25 also demonstrates that the pattern $\hat{8}-4 \hat{7}-\hat{6}-$ $\# \hat{7}-\hat{8}$ over $C \#$ appears across a longer span, $\mathrm{mm}$. 42-47. This contrapuntal progression begins in the bass in $\mathrm{mm}$. 42-44 as $C \#-B \#-B \#$. At $\mathrm{mm}$. 44-45, a voice exchange between $B$ and $E \#$ transfers $B$ from the bass to the upper voice (note the crossing lines in Figure 25, mm. 42 47). And just as $B \natural$ appears locally in $\mathrm{mm}$. 38-41 to tonicize IV, so it returns in $\mathrm{mm}$. 44-45 to 
simulate a larger tonicization of $F \#$. With the arrival of this IV on the downbeat of $m .46, B \#$ ultimately finds its way back to $B \#$ in the soprano voice (via $A \#$ ) while the bass continues its

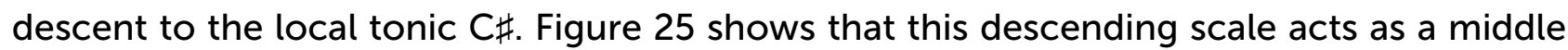
voice above a conceptual tonic pedal. Crucially, the insertion of $E \#$ at $m .46$ anticipates the change of mode to $\mathrm{C} \#$ minor at $\mathrm{m} .47$.

On reaching this $C \#$ minor in $m$. 47, Beethoven produces a modulatory effect not seen anywhere else in these preludes. Having ascended by octave $C \#-C \#$ in the bass across $\mathrm{mm}$. 47-50 (third graph in Figure 25), he inserts a first inversion D major chord in the second half of $\mathrm{m}$. 50. This sonority initially appears as 4 ll in $C \#$ minor but subsequently serves as a local tonic in D major (this is shown in the harmonic analysis of Figure 23). Although Beethoven hints at a cadence in D major in $\mathrm{m}$. 52 through a II - V7 progression, the tonic never materializes. Instead, he tonicizes B minor (shown in brackets in Figure 23), thereby setting up the next modulation, this time from $D$ major to $G$ major. This $B$ minor chord, which enters on the third beat of $\mathrm{m}$. 53, can actually be viewed as a displaced $\mathrm{G}$ chord in first inversion, in which the $F \#$ of the top voice shifts from a 5 th 

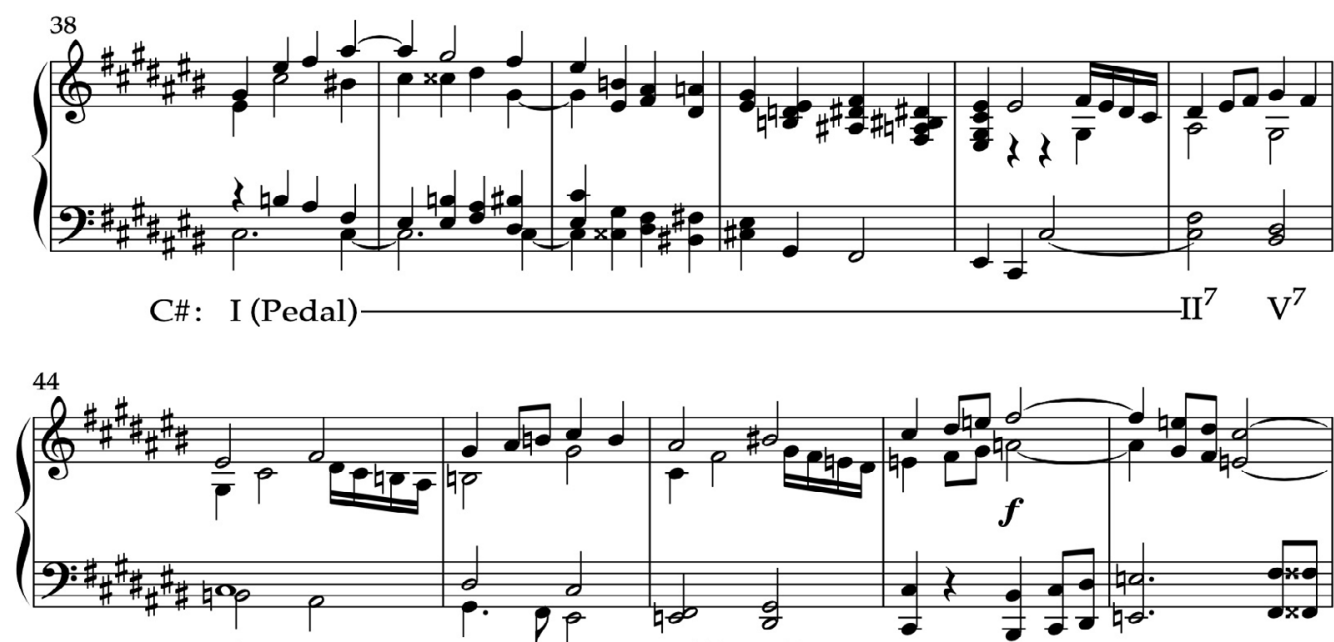

$\frac{\mathrm{C \#}: \mathrm{I}^{\natural 7} \ldots \ldots \mathrm{IV}^{\natural 7} \mathrm{~V}^{7}}{\left(\mathrm{~F} \#: \mathrm{V}^{7} \ldots \ldots \ldots \mathrm{I}^{\natural 7}\right) / /} \quad \mathrm{I}(\mathfrak{\ldots} 3)$
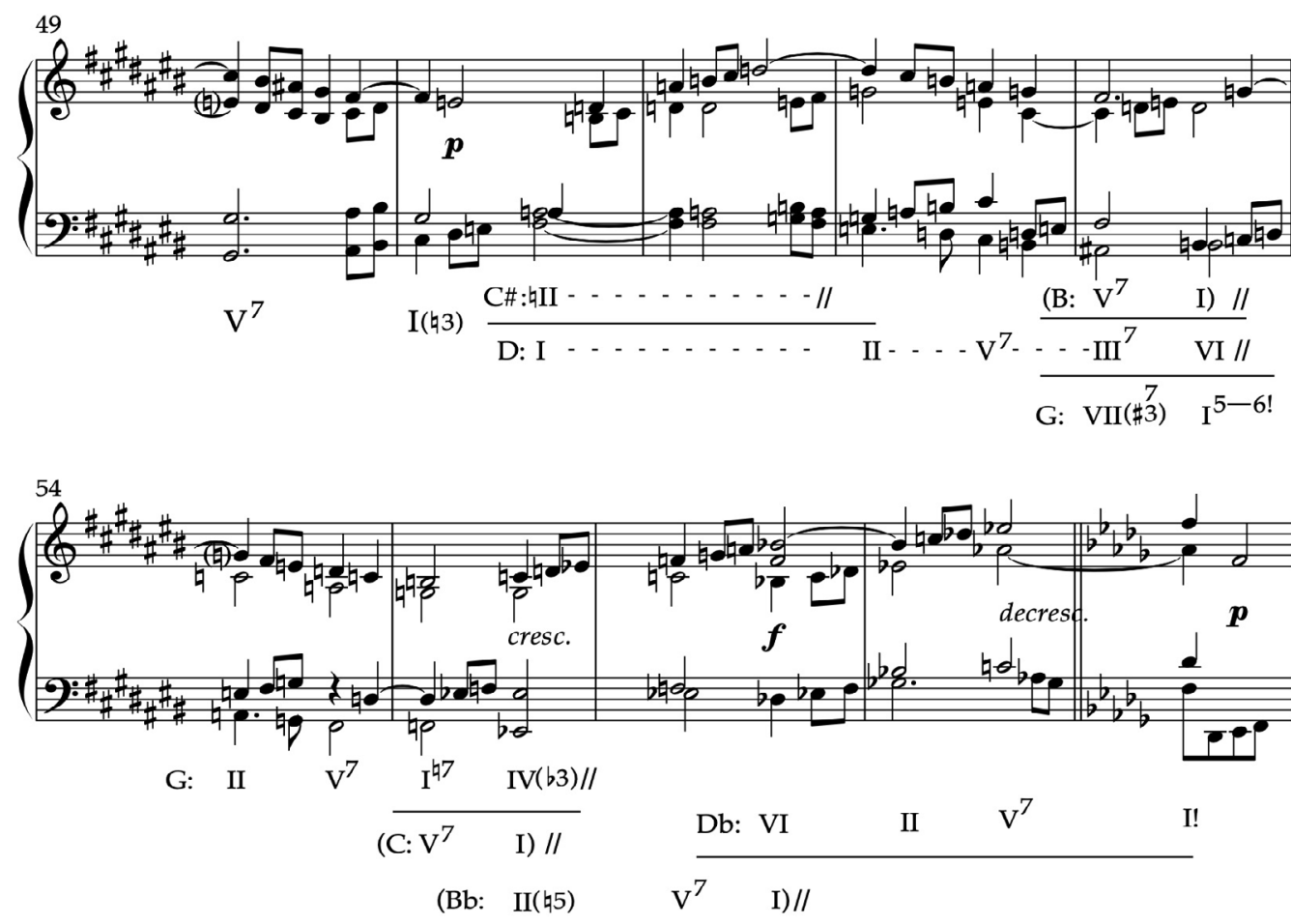

Figure 23: Beethoven Op. 39/1, mm. 38-58 (with detailed harmonic analysis). 


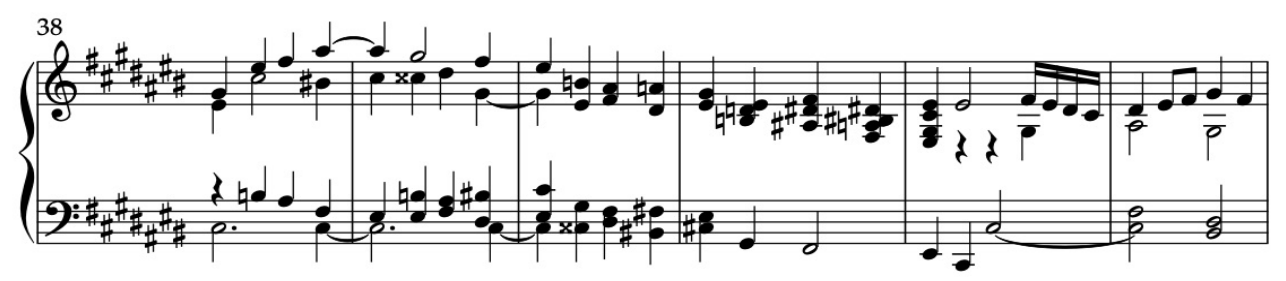

C\# : I $\$ 3)$

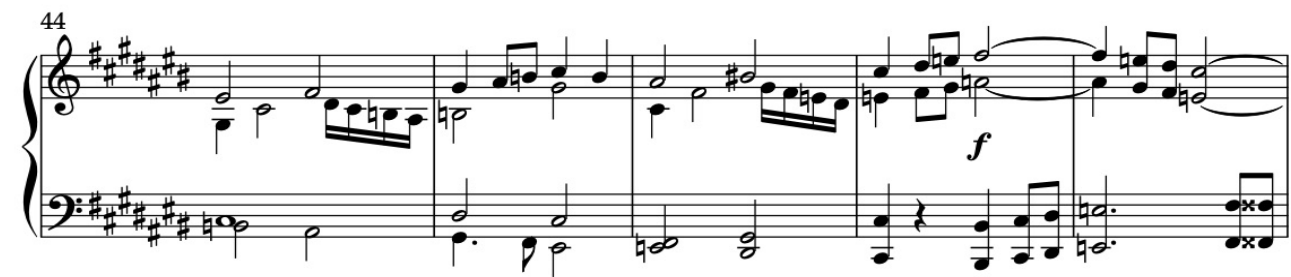

(43)
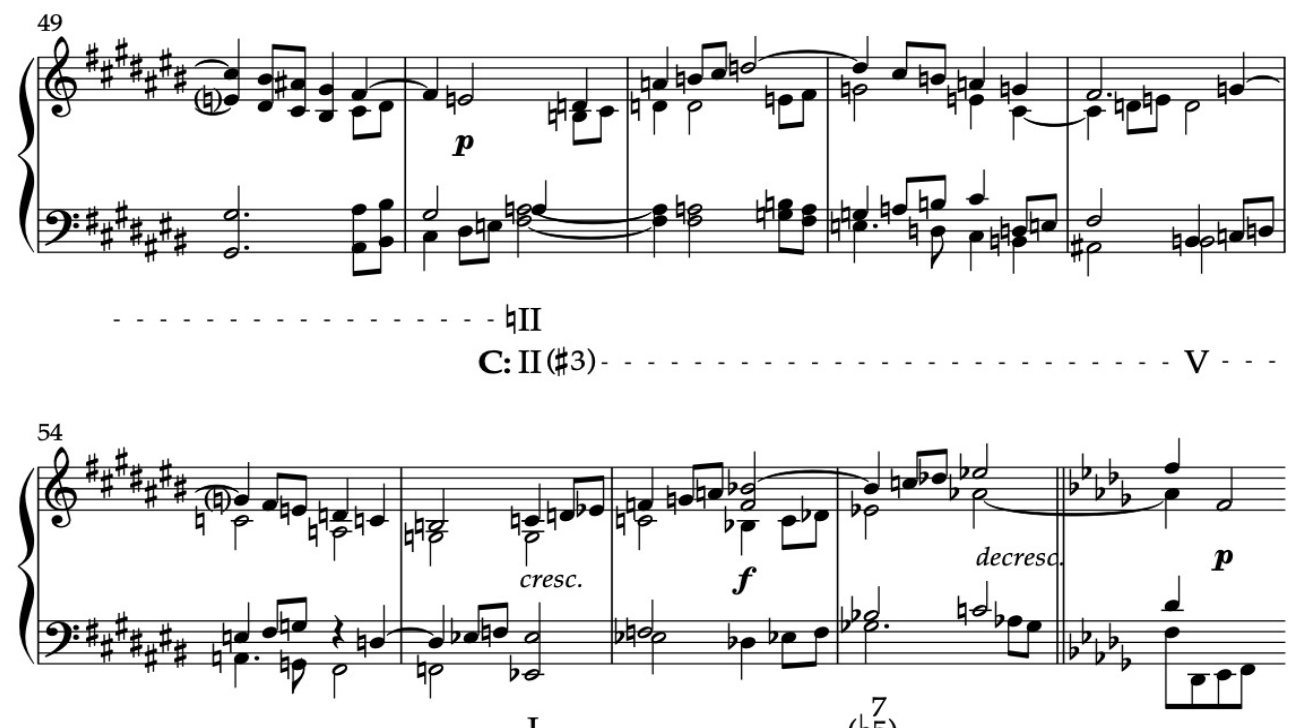

(b5)

Db: VII( 45$)$

$-\left(b^{7}\right)$

$\mathrm{V}^{7}$

I!

Figure 24: Beethoven, Op. 39/1, mm. 38-58 (with bird's eye harmonic analysis). 

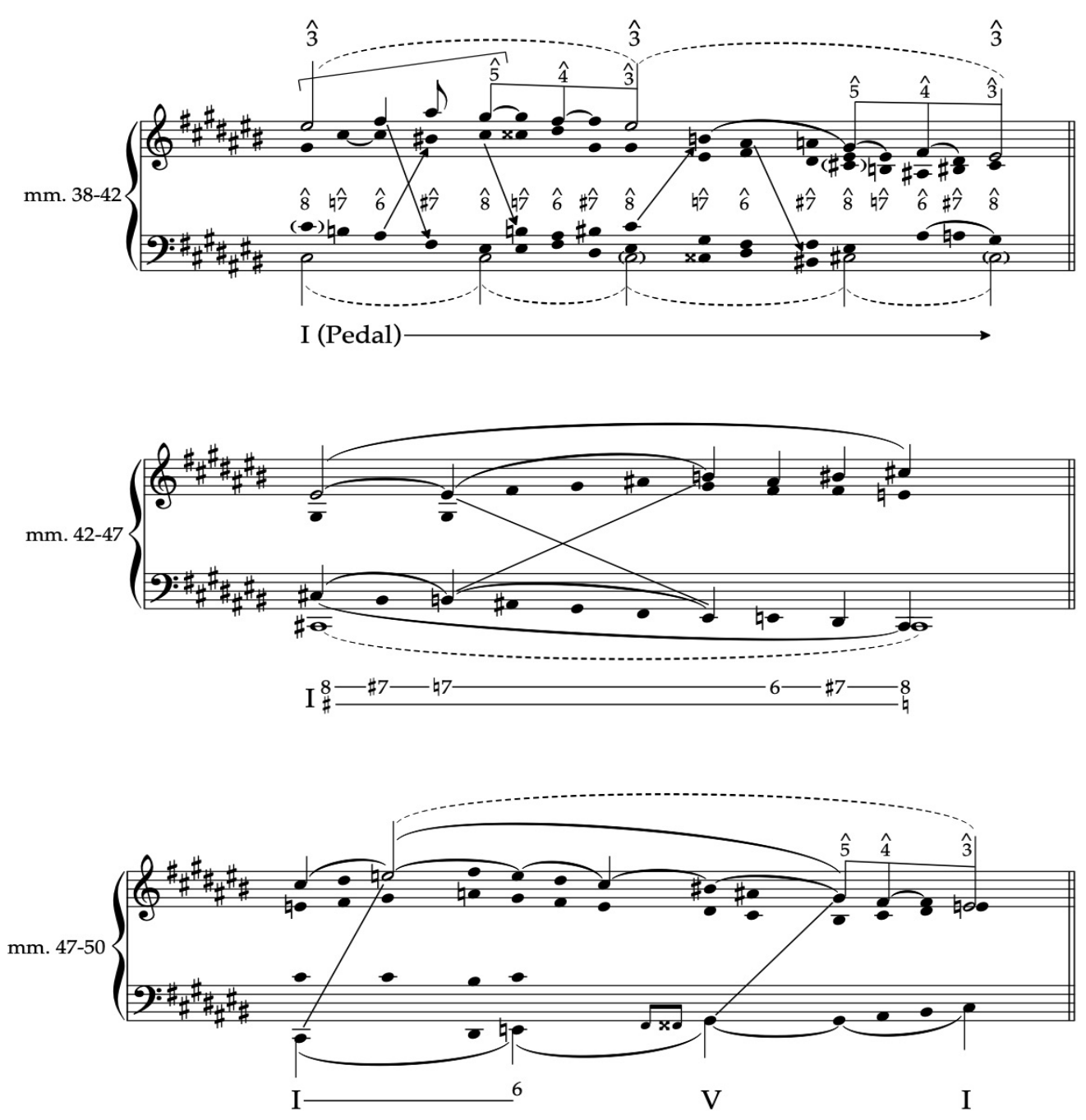

Figure 25: Beethoven, Op. 39/1, mm. 38-50, graphic analysis (in three segments).

to a 6th above the bass (note the "5-6!" in Figure 23). This strategy recalls the cadential trick Beethoven rehearsed in m. 21 (compare Figure 21), where A\# in the bass denies the resolution to $D$ and initiates the new modulation up a fifth. In $\mathrm{m}$. 53, however, by absorbing the $\mathrm{B}$ minor sonority, the $\mathrm{G}$ major chord reverses the direction of the modulation so that it shifts down a fifth. Another II - V progression appears, now in G major, but once again, the resolution to a consonant tonic sonority is averted: the tonic chord is transformed into a seventh on the downbeat of $\mathrm{m} .55$ by the addition of $\mathrm{F}$ in the bass. This sonority now tonicizes $C$ minor (in first inversion), thereby continuing the downward motion by fifth, and even touching upon the opening tonic once again for the first time (albeit in minor). As before, the averted cadential moment becomes the means by which a harmonic reinterpretation takes place: the $\mathrm{C}$ minor chord can immediately be reinterpreted as II 55 in $\mathrm{Bb}$ minor (Figure 23, $\mathrm{mm}$. 55-56), which allows the $\mathrm{Bb}$ chord of $\mathrm{m}$. 56 to serve as $\mathrm{VI}$ in $\mathrm{Db}$ major and initiate the progression II-V-I in the latter key. 
But one could just as easily turn the interpretation around and privilege $C$ minor as the larger composed-out essential harmony of $\mathrm{mm}$. 55-57, as shown in Figure 24. Just like the fleeting tonicization of $\mathrm{B}$ minor at $\mathrm{m} .53$, the tonicization of $\mathrm{Bb}$ minor is now subsumed by a larger modulation from $\mathrm{C}$ minor to $\mathrm{Db}$ major. This creates a smoother connection from the previous $\mathrm{G}$ major (the evaded cadences of $\mathrm{mm} .53$ and 55 now forming parallel events) and gives more balance to the deeper progression of essential harmonies: namely, $\mathrm{D}$ major ( $\mathrm{mm}$. 50-53); G major (mm. 53-55); and C minor (mm. 55-57), all of which can in fact be viewed as forming a large-scale auxiliary II-V-I progression in C minor. Figure 24 is designed specifically to show this larger modulatory effect from $\mathrm{C}_{\#}$ major/minor, through $\mathrm{C}$ minor, and onwards to $\mathrm{Db}$ major.

Beethoven's decision to use D major, G major, and $C$ minor chords as a pathway from $\mathrm{C} \#$ major to $\mathrm{Db}$ major is especially significant for understanding the passage's underlying voice-leading. In his Beiträge zur Modulationslehre Reger also used chords on $D, G$, and $C$ to modulate from $C \#$ major to $D b$ major. As shown in Figure 26, Reger interpreted the $D$ and $G$ chords in C minor: D as V/V (reinterpreted from a Neapolitan chord in C\#, or "IV6 $6 / 4$ "); ${ }^{20} \mathrm{G}$ as $\mathrm{V}$; and $\mathrm{C}$ as $\mathrm{I}$. He then described the shift to $\mathrm{Db}$, labelling the " $\mathrm{F}$ minor" chord in first inversion on beat four (this is indicated by the line under the Roman Numeral) as simultaneously IV in $\mathrm{C}$ and III in $\mathrm{Db}$, and connecting it to the upcoming $\mathrm{V}-\mathrm{I}$ cadence in $\mathrm{Db}$. With the exception of this "F minor" chord (which is better viewed as a contrapuntal elaboration of the Ab chord), this string of chords follows the same path as those in Beethoven's prelude (compare with Figure 24). The important difference is that Reger, like Jadassohn before him, treated his modulation as a literal, chord-by-chord succession-further reified (even "ossified") using music notation and contrived voice-leading-rather than, as we suggest, a succession of essential harmonies composed out by means of counterpoint and chromatic alteration.

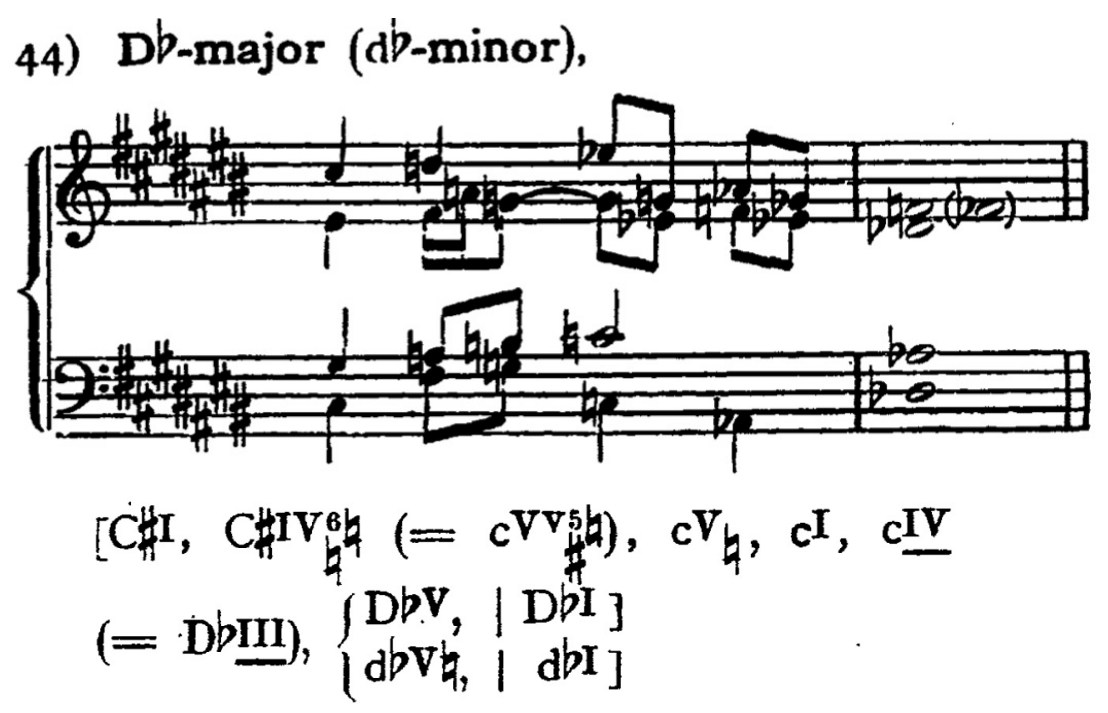

Figure 26: Reger's modulatory scheme from C\# major to Db major.

20 The difference between labeling the D chord as "IV" or "II" is inconsequential, as it amounts here to the same thing. And whether one wishes to call it a "secondary dominant" (as Reger does) or simply as a single Stufe is also largely beside the point. 
It should now be clear that the passage from $\mathrm{m}$. 38 to $\mathrm{m}$. 58 does not simply mark a shift in notation from $\mathrm{C} \#$ to $\mathrm{Db}$ major; it actually modulates from $\mathrm{C} \#$ to $\mathrm{Db}$-or at least simulates such a modulation by means of other transitory keys and chords. And that modulation takes place by means of C minor, the leading tone to Db (hence its analysis as "VII" in Figure 24). Although Reger and Schenker, at least in 1906, would both have acknowledged this modulation, they would have disagreed about how they viewed it. At least for Schenker, the surface effect of the modulation would be absorbed into the Diatonie of a later level, at which point $\mathrm{C} \#$ and $\mathrm{Db}$ would in fact be considered enharmonically equivalent.

Figures 27 and 28 describe how this process takes place. Proceeding from the local to the global, Figures $27 a-b$ demonstrate how the tonicized keys of D major and G major are solidified contrapuntally and harmonically: each involves the familiar stepwise decent $\hat{5}-\hat{4}-\hat{3}$ in the upper voice supported by an auxiliary progression $16-V 6 / 5-I$. Since, as explained above, neither D nor G receives resolution, the final "I" chords are placed in brackets along with the corresponding notes. Figure $27 c$ then shows how the local descent $\hat{5}-\hat{4}-\hat{3}$ transfers to the lowest voice to tonicize $\mathrm{C}$ minor, $\mathrm{Bb}$ minor, and finally $\mathrm{Db}$ major (in each case, the initial " $\hat{5}$ " is elided). Significantly, the upper voice in this last sketch projects a large-scale ascent from $C$ to $F$. This rising fourth (as well as its inversion) appear in diminution throughout the prelude: it is manifest in the opening head motive of the subject ( $\mathrm{m}$. 1ff, see Figure 18a); the modulation from $D$ to A (m. 25, see Figure 21); the modulation in mm. 31-33 (see Figure 22b); and the $\mathrm{C} \#$ major section starting at $\mathrm{m}$. 42. When the motive enters in Figure 27c it marks the highpoint of the entire prelude up to this point.

As a last step, Figure 28 gives middle- and foreground analyses of mm. 50-58. The former provides a synoptic view of the passage and, among other things, highlights two concealed motivic repetitions: the ascending fourth motive in the soprano (discussed above); and the opening motive of the second prelude in the inner voice ( $\mathrm{C} \#-\mathrm{Eb}-\mathrm{Gb}-\mathrm{F})$. Meanwhile, the latter elaborates the middleground sketch. Besides reinstating the original registers, it integrates the local D major and G major tonicizations of Figures 27a-b, and it reveals the full scope of the ascending fourth motive in the upper voice $(C-D b-E b-F)$ as the composing out of $a$ tenth ( $C$ to $E b$ ) plus a step. It also shows the correspondence with the bird's eye harmonic analysis of Figure 24 (now using letters for the root progression). Both sketches demonstrate how the octave descent in the bass supports a motion to and from the local Kopfton E\#/FG () in the upper voice. The bass descent is, of course, anticipated at the surface-level by the descending and ascending scales in mm. 42-47 and 47-50. At the deeper level, however, the initial bass $C \#$ operates up until the third beat of $m$. 52 using a 5-6 shift (as shown at the middleground), from which it begins to descend at the evaded cadential moment on $B(\mathrm{~m}$. 53 , beat three); a series of descending $6 / 3$ chords then ensues up to the $\mathrm{Eb}$ of $\mathrm{m}$. 55 (beat three), the arrival of the $\mathrm{C}$ minor chord. Given the composing-out of a transformed $\mathrm{C}$ chord between $\mathrm{mm} .55$ and 57 (as explained above), the last step in the descending octave (Eb to $\mathrm{D}$ ) is drawn out-it is only with the arrival of $\mathrm{Db}$ major in $\mathrm{m} .58$ that the descending octave completes itself. In sum, both the effect of modulation, one full of musical fantasy, and a deeper composing-out of a single chord have been achieved in this passage. 

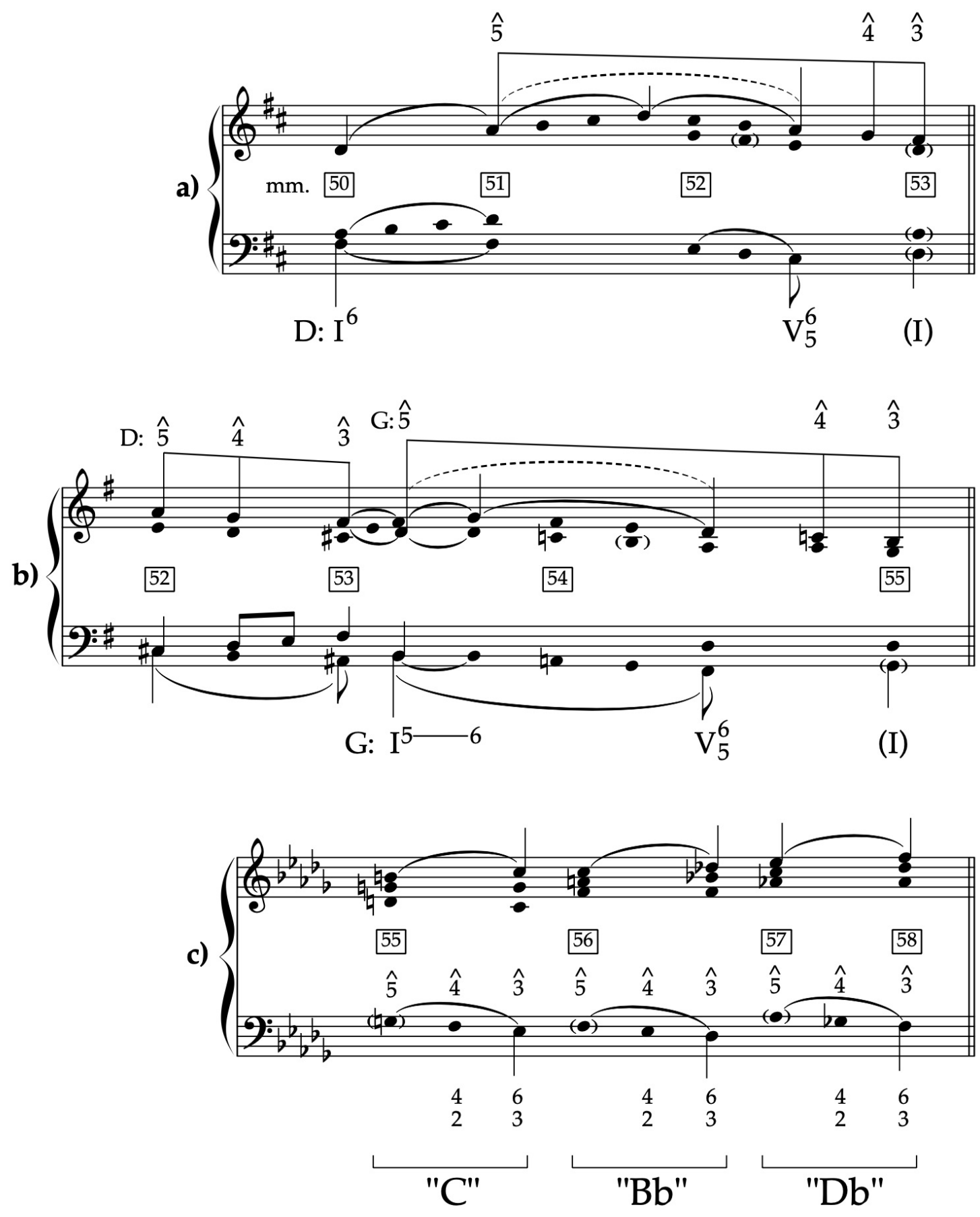

Figure 27: Beethoven, Op. 39/1, mm. 50-58. 

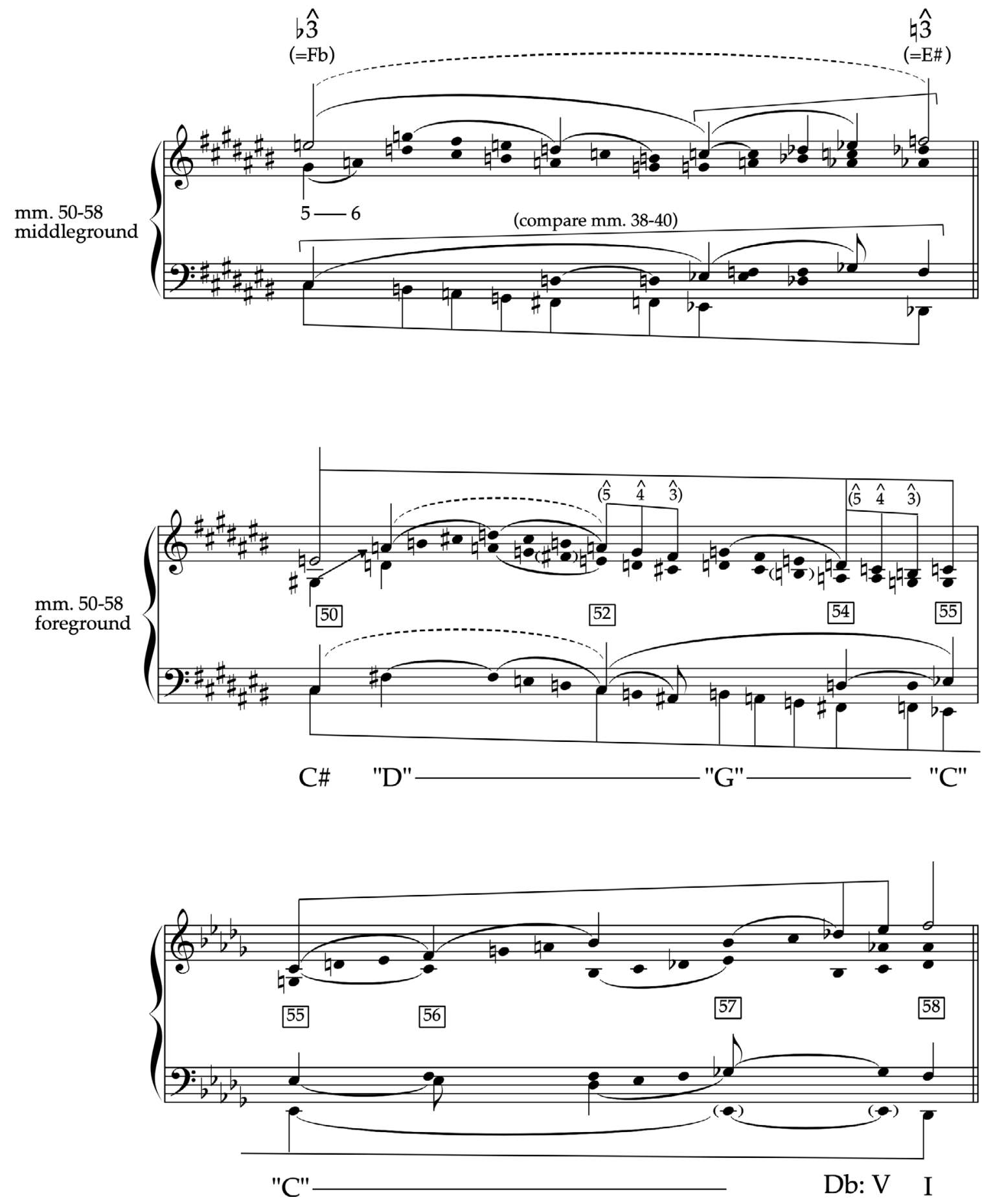

Figure 28: Beethoven, Op. 39/1, mm. 50-58 (middleground and foreground).

More can surely be said about the significance of modulation in Beethoven's Preludes Op. 39 , but the preceding comments have shown that modulation plays a vital role in shaping the surface of tonal compositions. Instead of perpetuating traditional approaches to key relationships, which often rely on the notions of relative, close, and distant keys, Schenker explained modulation contrapuntally, claiming that secondary key areas ultimately arise at the foreground for melodic, even motivic reasons. Assigning modulations to the foreground 
does not mean that they are unimportant or irrelevant to the structure of a musical composition; on the contrary, it simply means that modulations emerge fairly late in the generative process, after other features of the harmony and voice leading. The idea that modulations are generated near the surface is not, in fact, particularly surprising because they often have significant formal implications and because Schenker also treated musical form as a foreground phenomenon in Part III Chapter 5 of Der freie Satz. As he put it most succinctly, "[a] Il forms appear in the ultimate foreground; but all of them have their origin in, and derive from, the background" (SCHENKER 1979 [1935], p.130).

\section{Wrapping up: Fantasizing at the Background}

The harmonic and voice-leading procedures discussed above are not, of course, unique to Beethoven's Op. 39 preludes. As a pupil of Neefe and a life-long disciple of C.P.E. Bach, Beethoven was fully immersed in the world of modulating, preludizing, and fantasizing. Not only had Beethoven worked on similar techniques in another prelude (F minor, WoO 55, c. 1803), but he had also incorporated such techniques on a small and large scale in his Fantasy, Op. 77. ${ }^{21}$ While Edward Laufer has pointed to the use of certain motives as the initiators of programmatic events in that work (LAUFER, 1988), John Rink has presented a graphic analysis that comes close to showing how the descending span $\hat{5}-\hat{4}-\hat{3}$ guides a large-scale modulation from Bb major to B major, the key in which the fantasy closes (see Figure 29; RINK, 1993, p.20). ${ }^{22}$ According to Rink, $\mathrm{B} b$ is secured as early as $\mathrm{m} .15$ and serves as the primary key until m. 77; it is then respelled enharmonically in $\mathrm{m}$. 88 as $A \#$ and serves as the leading tone to $B$.

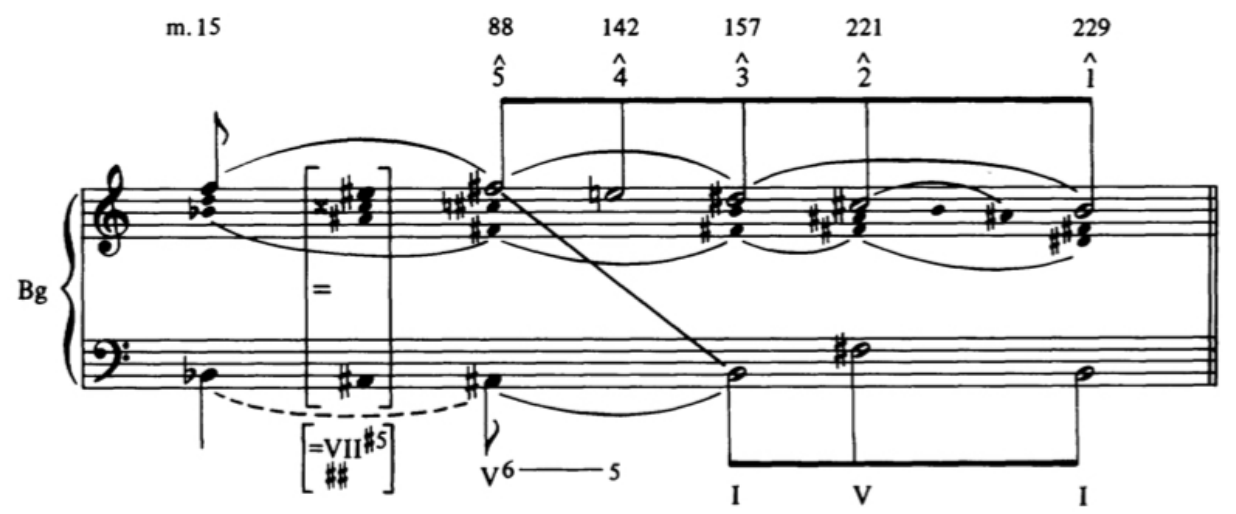

Example 5. Beethoven, Fantasy, Op. 77. Background structure.

Figure 29: John Rink's Background Analysis to Beethoven's Fantasy, Op. 77. 


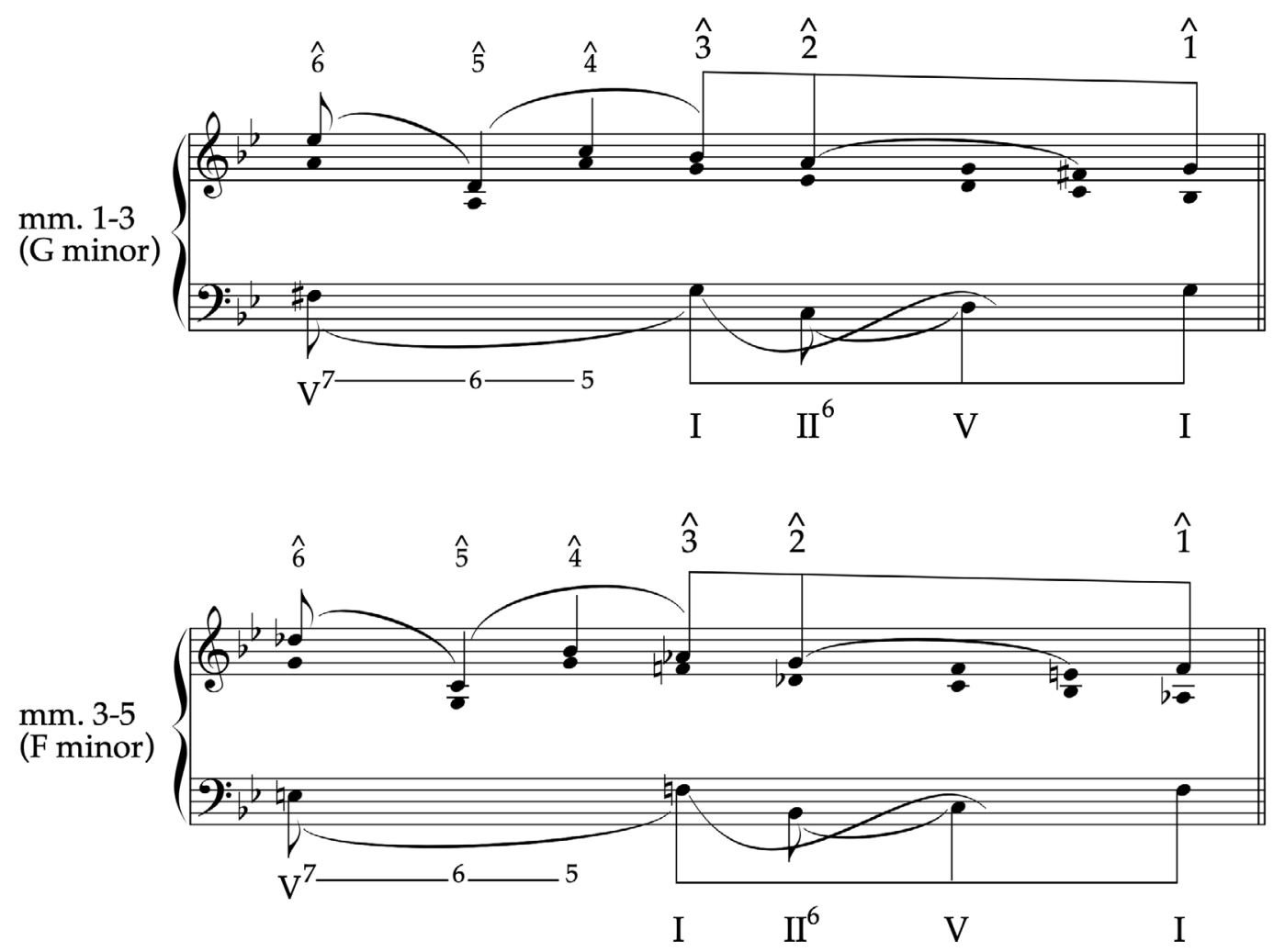

Figure 30: Beethoven Fantasy, Op. 7, mm. 1-5 (graphic analysis).

Not mentioned by Rink, Figure 30 shows that the opening of the Fantasy actually mirrors the global progression of Figure 29: an initial $\hat{5}-\hat{4}-\hat{3}$ in the upper voice is supported by $7^{\wedge}-1^{\wedge}$ in the bass. Just like many of the modulatory passages of the Op. 39 preludes, is anticipated by an incomplete neighbor on $6^{\wedge}$, in this case supported by the local diminished seventh chord. Beethoven does this first in $\mathrm{G}$ minor and then in $\mathrm{F}$ minor, each time eliding an initial local tonic.

Although the Fantasy is typically thought to be "in" G minor, G minor is only the starting key of the opening three measures. As Rink suggests, it is better understood as initiating an auxiliary progression in $\mathrm{Bb}$ major. Figure 31 shows, in fact, that the auxiliary progression from $\mathrm{G}$ to $\mathrm{Bb}$ produces yet another manifestation of $\hat{5}-\hat{4}-\hat{3}$ in the upper voice (with an initial as incomplete upper neighbor), this time accompanied by $\hat{6}-b \hat{7}-\downarrow \hat{7}-\hat{8}$ in the bass (a fragment of the $\hat{8}-\hat{7}-\hat{6}-\hat{7}-\hat{8}$ motive). ${ }^{23}$ In the case of Figure 29 , Rink treats the top-voice $\mathrm{F}$ above $\mathrm{Bb}$ at m. 15 as an incomplete lower neighbor to $F \#$ (enharmonically respelled as E\# in brackets), and in B major as the Kopfton. Alternatively, Figure 31 treats $F(m .14)$ and $F \#(m .93)$, in their respective keys of $\mathrm{Bb}$ major and $\mathrm{B}$ major, like the opening auxiliary progressions in $\mathrm{G}$ minor and $\mathrm{F}$ minor: as a third span $\hat{5}-\hat{4}-\hat{3}$ in the upper voice that anticipates $\hat{3}$, the point of departure for descent of the "Urlinie." Since the fantasy starts and ends in different keys, the final $\hat{3}-\hat{2}-\hat{1}$ only takes place in B major. ${ }^{24}$

\footnotetext{
$23 \hat{4}(E b)$ is interpreted in this case as an implied passing tone between $\mathrm{m} .14$ and $\mathrm{m} .15$ (conceptually, within the space of the fermata following the cadenza at m. 14).

24 Carl Czerny, a pupil of Beethoven, makes use of a similar modulatory technique from B major to B major at the opening of his Fantasy, which is dedicated to Beethoven.
} 


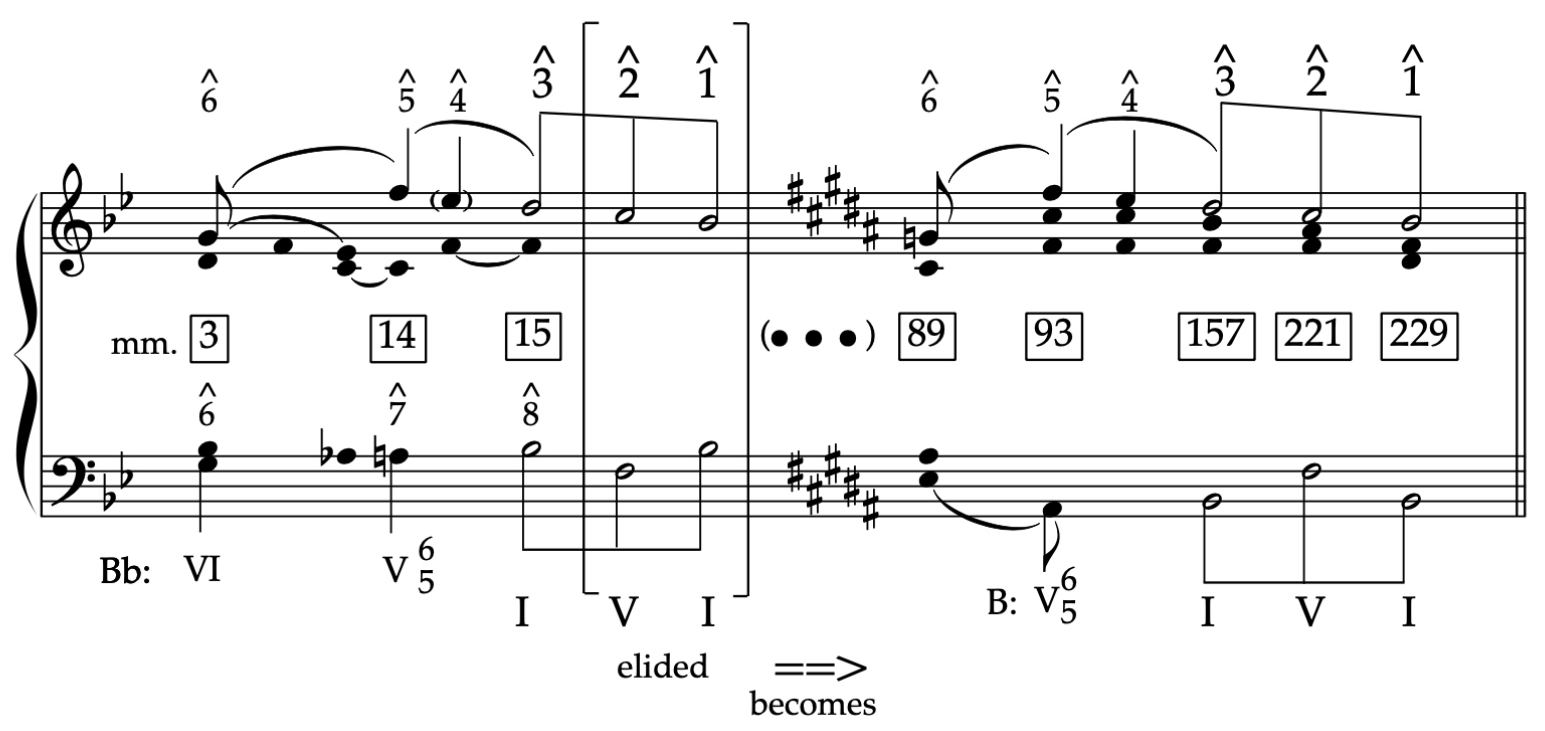

Figure 31: Alternate deep middleground to Beethoven, Op. 77.

We have mentioned how Beethoven was steeped in a tradition of modulating, preludizing, and fantasizing that can be traced back through his teacher Christian Gottlob Neefe to C.P.E. Bach. But the story does not end there. As mentioned earlier, Beethoven perpetuated this tradition by teaching his students to do precisely the same. Ferdinand Ries, who studied with Beethoven in Vienna after he arrived in the city in the winter of 1801/1802, composed a collection of 40 preludes Op. 60 for piano "in many major and minor keys, which serve as introductions to all of the movements" (ca. 1815). Similarly, Carl Czerny recalled in his autobiography how he first met Beethoven when he was ten years old and soon started to study with him. Beethoven apparently required him to acquire a copy of "Emanuel Bach's book on the true art of clavier-playing" before the start of the first lesson (CZERNY, 1956 [1842]). Czerny went on to publish his own treatises of preludizing and modulation: in 1829, he completed the Systematische Anleitung zum Fantasieren auf dem Pianoforte Op. 200 and a few years later a companion volume on Die Kunst des Praludierens, Op. 300. Both the former, but especially the latter, included examples of preludes that modulate to every possible key! Given his familiarity with Czerny's editions of music by Bach, Beethoven, and Scarlatti, not to mention his manuals on piano technique, it is quite possible that Schenker knew or knew about these treatises on modulation and preludizing. And, although it is unclear whether he would have approved of Czerny's own improvisations, Schenker would surely have approved of his approach to teaching music theory. 


\section{REFERENCES}

BACH, C.P.E. Versuch über die wahre Art das Clavier zu spielen. Berlin: Winter, 1759, 1762. Tr. by W. MITCHELL as Essay on the True Art of Playing Keyboard Instruments. London: Eulenburg, 1974.

BLUMRÖDER, C. 1972. Modulatio / Modulation. In Handwörterbuch der musikalischen Terminologie, ed. by H. EGGEBRECHT, v.4, p.1-20, 1983.

BROWN, M, HEADLAM, D., DEMPSTER, D. The \#IV(bV) Hypothesis: Testing the Limits of Schenker's Theory of Tonality. Music Theory Spectrum, v.19, n.2, p.155-183, 1997.

CAEYERS, J. Beethoven: A Life, tr. by B. ANNABLE. Berkeley, CA: University of California Press, 2020.

COOK, N. The Schenker Project. Oxford: Oxford University Press, 2007.

CZERNY, C. "Recollections from My Life" [1842], tr. E. SANDERS, The Musical Quarterly, v. 42, n.3, p.302-317, 1956.

GJERDINGEN, R. Music in the Galant Style. New York: Oxford University Press, 2007.

GREEN, J. F. New Hess Catalog. West Newberry, VT: Vance Brook Publishing, 2003.

HINTERBERGER, H. Enthaltend die Bibliothek des Herrn Dr. Heinrich Schenker. Wien Katalog XII. Vienna: Antiquariat Hinterberger, 1935.

JADASSOHN, S. Die Kunst zu Modulieren und zu Präludieren. Leipzig: Breitkopf und Härtel, 1890.

Lehrbuch der Harmonie. Leipzig: Breitkopf \& Härtel, 1883.

JONAS, O. Das Wesen des musikalischen Kunstwerks: Einführung in die Lehre Heinrich Schenkers. Vienna: Saturn-Verlag, 1934. Ed. and tr. by J. ROTHGEB as Introduction to the Theory of Heinrich Schenker. New York: Longman, 1982.

LAUFER, E. On the Fantasy. Intégral v.2, p.99-133, 1988.

LOUIS, R.; THUILLE, L. Harmonielehre. Stuttgart: Carl Grüninger Verlag, 1907. 
MITCHELL, W. J. Modulation in C.P.E. Bach's Versuch. In Studies in Eighteenth-Century Music, ed. H.C. ROBBINS LANDON and R.E. CHAPMAN. London: George Allen, p.333-342, 1970.

QUANTZ, J.J., Versuch einer Anweisung die Flöte traversiere zu spielen. Berlin: Voss, 1752. Tr. by E. R. REILLY as On Playing the Flute. New York: Schirmer, 1985.

RASCH, R. The Musical Circle: From Alfonso to Beethoven. The Dutch Journal of Music Theory v.2, n.2, p.110-133, 1997.

RINK, J. Schenker and Improvisation. Journal of Music Theory v.37, n.1, p.1-54, 1993.

REGER, M. Beiträge zur Modulationslehre. Leipzig: C. Kahnt, 1903.

SALZER, F. Haydn's Fantasia from the String Quartet, Opus 76, No. 6. The Music Forum 4, p.161-194, 1976.

SCHACHTER, C. Analysis by Key: Another Look at Modulation. Music Analysis 6/3 (1987), pp.289-318.

SCHENKER, H. Harmonielehre. Stuttgart and Berlin: Cotta, 1906. Tr. by E. MANN-BORGESE and ed. by O. JONAS as Harmony. Chicago: Chicago University Press, 1954.

SCHOENBERG, A. Structural Functions of Harmony. Rev. ed. Leonard Stein. New York: W. W. Norton, 1969.

Kontrapunkt I. Stuttgart and Berlin: Cotta, 1910. Ed. John Rothgeb and tr.

J. ROTHGEB and J. THYM as Counterpoint. Ann Arbor, MI: Musicalia, 2001.

Die Kunst der Improvisation. In Das Meisterwerk in der Musik v.l. Munich: Drei Masken Verlag, p.11-40, 1925. Tr. by R. KRAMER as The art of improvisation. In The Masterwork in Music v.1, ed. by W. DRABKIN. Cambridge: Cambridge University Press, 2-19, 1994.

Ein Gegenbeispiel: Max Reger, Op. 81, Variationen und Fuge über ein Thema von Joh. Seb. Bach für Klavier. In Das Meisterwerk in der Musik v.II. Munich: Drei Masken Verlag, p.173-192, 1926. Tr. by J. ROTHGEB as A counter-example: Max Reger's Variations and Fugue on a Theme by Bach, Op. 81, for piano. In The Masterwork in Music v.1, ed. by W. DRABKIN. Cambridge: Cambridge University Press, p.106-117, 1994.

Der freie Satz. Neue musikalische Theorien und Phantasien 3. Vienna: Universal, 1935. Tr. by E. OSTER as Free Composition. New York: Longman, 1979. 
SOLOMON, M. Beethoven's Productivity at Bonn. Music and Letters, v.53, n.2, p.165-172, 1972.

SWAFFORD, J. Beethoven: Anguish and Triumph. New York: Houghton Mifflin, 2014.

WASON, R. W.; BROWN, M. Heinrich Schenker's Conception of Harmony. Rochester, NY: University of Rochester Press, 2020. 